\title{
Neurologic and inflammatory manifestations in Sjögren's syndrome: the role of tryptophan/kynurenine pathway
}

Fabíola Reis de Oliveira ${ }^{1}$, Marina Zilio Fantucci ${ }^{1}$, Leidiane Adriano ${ }^{1}$,

Valéria Valim², Thiago Mattar Cunha ${ }^{1}$, Paulo Louzada Junior ${ }^{1}$,

Eduardo Melani Rocha ${ }^{1}$

${ }^{1}$ Ribeirao Preto Medical School, Ribeirao Preto, University of Sao

Paulo, Ribeirao Preto, SP, Brazil.

2Espírito Santo Federal University, Vitoria-ES, Brazil.

Financial Support: FAPESP, CNPQ, FAEPA, CAPES

Corresponding Author:

Eduardo Melani Rocha

Department of Ophthalmology, Otorhinolaryngology and Head \& Neck

Surgery, RibeirãoPreto Medical School, University of São Paulo.

Av. Bandeirantes, 3900, 14049-900 - Ribeirão Preto SP, Brazil.

emrocha@fmrp.usp.br

Phone/fax: 55-16-3602-0593

The authors have no commercial or proprietary interest in any concept or product described in this article. 


\begin{abstract}
For decades, neurologic, psychological and cognitive alterations, and other extra glandular manifestations have been described and are being considered part of the Sjögren's syndrome (SS). The lacrimal glands (LG), the ocular surface (OS), salivary glands (SG) and the central nervous system (CNS) are integrated to modulate the autonomic functions and the hippocampus, which is linked to the autonomic nervous system, modulate behavior responses compromised in the SS.

Recent studies confirm that the tryptophan/kynurenine pathway (TKP) can be stimulated by interferon- $\mathrm{Y}(\mathrm{IFN}-\mathrm{\gamma})$ and other cytokines, activating the indoleamine-pyrrole 2,3-dioxygenase (IDO) in SS. This pathway interferes on serotonergic and glutamatergic neurotransmission, mostly in the hippocampus, and other structures of the CNS. Therefore, it is plausible that TKP induces neurological manifestations, and contributes to the discrepancy between symptoms and signs, including manifestations of hyperalgesia and depression in patients with SS, for example. Observations from clinical studies in AIDS, graft versus host disease, lupus and SS, but also from experimental studies support this hypothesis. Therapeutic strategies are reexamined and new options designed and tested to regulate the TKP. In the future, the confirmation and application of this concept may offer a clue to the mosaic of manifestations of SS.
\end{abstract}

Key words: IDO, kynurenine, pain, Sjögren's syndrome, tryptophan 


\section{Outlines}

1. Introduction

2. Autoimmunity, neuropathy and chronic pain

\section{2.a. SS and Neurological manifestations}

\section{2.b. SS and the mechanisms of neurological manifestations}

2.c. The immune and the endocrine modulation of neurological

\section{findings in SS}

3. The tryptophan/kynurenine pathway (TKP)

4. The TKP and the neurologic manifestations

4.a. The role of the hippocampus in the TKP ofthe neurologic manifestations

5. The TKP and the neuropathy in SS

6. Therapy to modulate the TKP

7. Future perspectives

8. Conclusions

9. References

10. Attachments: Box, Tables and Figures legends

11. Abbreviations: 5-HT: serotonin, APCs: antigen-presenting cells, ASA: acetyl salicylic acid, CIDP: chronic inflammatory demyelinating polyradiculoneuropathy, CNS: central nervous system, EGM: extraglandular manifestations, GVHD: graft-versus host disease, hCDR1: human complementarity determining region 1, HCG: human chorionic gonadotropin, IDO: indoleamine 2,3-dioxygenase, IFN-ץ: Interferon- $\gamma$, KAT: kynurenine aminotransferase, KMO: Kynurenine 3, LFU: lacrimal functional unit, LG: lacrimal gland, LTF: L-tryptophan, NAD+: 
nicotinamide adenine nucleotide, NAISD: non-steroidal antiinflammatory drugs, NMDA: N-methyl-D-aspartate, OAS1: 2-5 oligoadenylate synthetase 1 PBC: primary biliary cirrhosis, PBMCs: peripheral blood mononuclear cells, PKM: pokeweed mitogen, PNS: peripheral nervous system, SLE: systemic lupus erythematosus, SLEDAI: Systemic Lupus Erythematous Disease Activity Index, SS: Sjogrën's syndrome, TDO: tryptophan 2,3-dioxygenase, TG: trigeminal ganglion, TKP: tryptophan/kynurenine pathway monoxygenase 


\section{Introduction}

Sjogrën's syndrome (SS) is defined as an exocrinopathy of salivary and lacrimal glands (SG and LG) mediated by autoimmune mechanisms that can manifest neurologic dysfunctions, and those neurologic dysfunctions may take part in the physiopathology of the disease [1-5]. However, the neurological manifestations are not considered in the definition or the diagnosis, despite those manifestations are present in the disease progress evaluation and are being reported in association with SS with more attention in recent years [6-9]. Of interest, $60-80 \%$ of patients develop neurological manifestations before or at SS diagnosis (early systemic presentation) indicating that neurological inflammatory damage is precocious and could have a role in disease mechanism [10].

The tryptophan/kynurenine signaling pathway (TKP) intermediates the serotonergic and glutamatergic neurotransmission. It is also known to take part in the inflammatory mechanisms of the neurogenic manifestations of autoimmune diseases through the action of indoleamine 2,3-dioxygenase (IDO), the rate-limiting enzyme in the tryptophan degradation [11-15].

This review summarizes the actual status of the knowledge of the neurological manifestations in SS and presents the hypothesis of the association between these neurological manifestations and the TKP (Box 1).

Box 1. Summary of evidences linking Sjögren's syndrome (SS) and the thryptophan/kynurenine signaling pathway (TKP) 
- $\quad$ Association among chronic inflammation, pain and neuropathic disorders

- $\quad$ Triggered by Interferon

- $\quad$ Modulated by sex hormones

- Tryptophan deprivation induces dry eye

- $\quad$ Sjögren's syndrome and salivary gland aggression leads to increased expression of kynurenine

\section{Autoimmunity, neuropathy and chronic pain}

Autoimmunity is linked to chronic neuropathy in at least three different forms. The first and major outcome observed is the pain, in its different dysfunctional manifestations, as allodynia, dysesthesia, hypo or hyperestesia and hyperalgesia $[9,16,17]$. Second, chronic inflammation in the target organs generates a noxious stimulus that may persist in a further phase where the inflammatory process is already resolved $[18,19]$. Third, the central nervous system (CNS), mostly the autonomic nervous system dysfunction can induce or perpetuate an unbalanced inflammatory response in the targetinnervated organs $[3,20]$. Therefore, an unified theory of the relationship between the neural and immune mechanisms of the SS manifestations take in account that lesions of the autonomic and peripheral neural system reduce the threshold for inflammatory and noxious events in their connected organs, and disturb the balance between pro and anti-inflammatory mediators [21-23] (Figure 1). 
Figure 1. A schematic model, showing the interrelationships among the autonomic nervous system dysfunction, pathological pain and chronic inflammation in Sjögren's syndrome (SS).

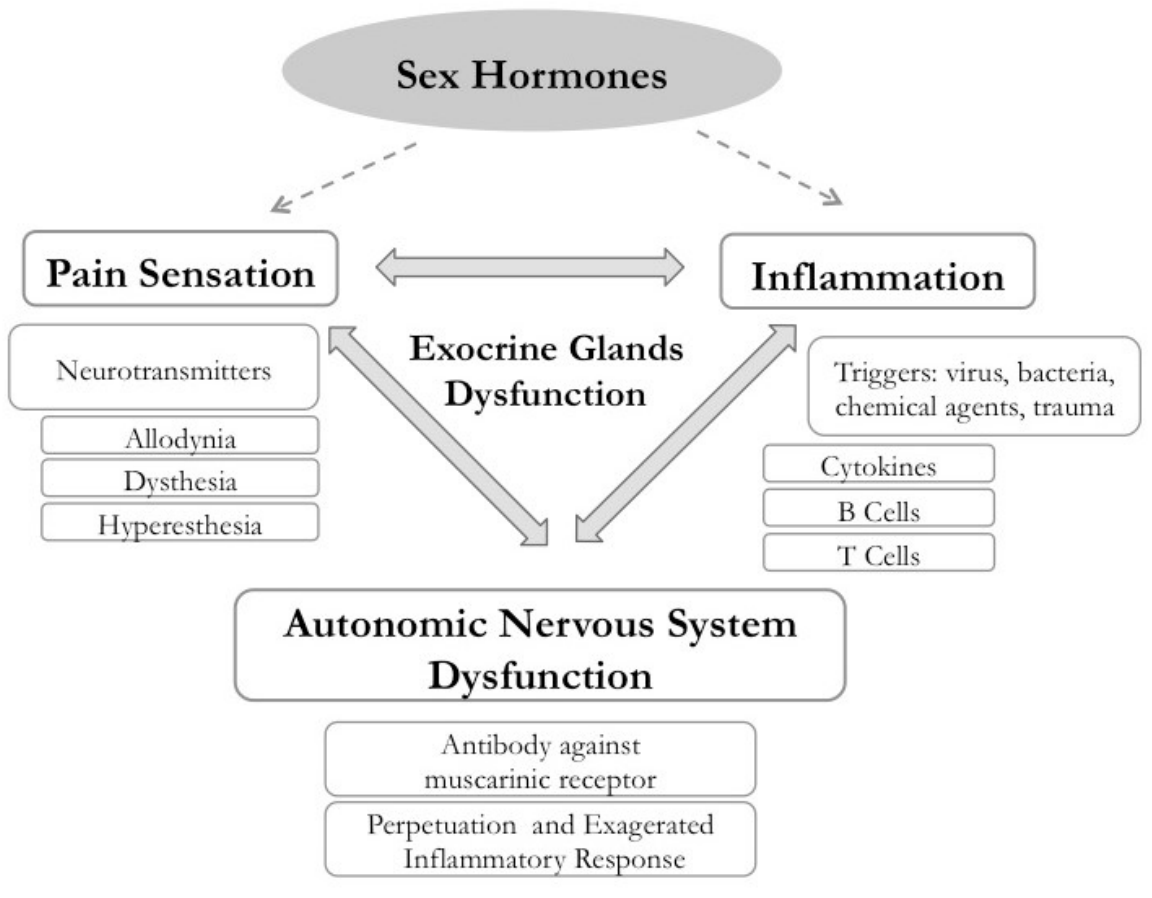

The chronic pain and persistent inflammation mediated by humoral factors and neurotransmitters associate autoimmunity and neuropathy in several target organs, including the hippocampus and the lacrimal functional unit (LFU) on SS [20,24-28]. The dissociation between signs and symptoms of dry eye and dry mouth delays and makes the diagnosis more difficult in SS but paradoxically, those individuals present a high association between pain sensation in different organs and dry eye and dry mouth [5,29-35].

Our hypothesis consider the TKP in the mechanism of SS neuropathy, since compensatory crosstalk pathways can drive the dissociation between signs and symptoms among the immune, the endocrine and the neural systems [36-41]. 
This hypothesis predicts a spectrum of manifestations with two different poles of the SS disease. In one pole, the major characteristic is the chronic non-inflammatory pain with neuropathic features. In the opposite pole, primary SS present with inflammatory activity, including extra-glandular manifestations (EGM). However, these profiles can only be documented in long-term cohort studies [42]. In other words, we hypothesized that SS patients with Interferon-y (IFN-ץ)-inducible TKP activation could develop chronic pain and low EGM disease activity because the TKP promotes an immunosupressive and neuro sensitive effect. Therefore IFN- $\gamma$-inducible TKP could be the missing link between disease activity and neural manifestations in SS [43] (Figure 1).

\section{2.a. SS and Neurological manifestations}

Neurological signs and symptoms have been described in SS. Peripheral neuropathy ranges from 8-49\%, depending on selecting bias related to different classification criteria, and whether neurologic manifestations were diagnosed based on clinical marked symptoms versus asymptomatic, or detected by electrophysiological studies $[2,44-$ 48]. Distal sensory and sensorimotor neuropathies are the most common manifestations of peripheral nerve disease in pSS. Sensory neuropathies include painful nonataxic sensory polyneuropathy, small fiber neuropathy, dorsal root ganglionitis, and trigeminal neuropathy.

Other forms are also described including multiplex mononeuritis, acute or chronic inflammatory demyelinating polyradiculoneuropathy (CIDP), multiple cranial neuropathy specially III, V, VI, VII, IX, X and 
XII and last but not least, dysautonomia, which is very common in SS, and can reach a frequency of $40 \%$ of SS patients, in combination or not with different neurological manifestations [49-52]. Moreover, CNS manifestations may cause focal syndromes (such as multiplesclerosis-like, epilepsy, movement disorders, neuromyelitis optica, and pseudotumor) and diffuse syndromes (encephalitis, meningitis, cognitive dysfunction, psychiatric disorders). Acute or chronic myelopathy and inferior motor neuron disease may also occur [44,45,49,53-58] (Table 1). 
Table 1. List of the main neurocognitive changes in Sjögren syndrome described in several study models

\begin{tabular}{|c|c|c|c|}
\hline Description of the disorder & Study model & $\mathbf{N}$ & Author, year \\
\hline Major depressive and panic disorder & Case series & 2 & Pelizza et al, $2010^{[59]}$ \\
\hline Visual hallucinations & Case report & 1 & Wong et al, $2014^{[60]}$ \\
\hline Dementia & Case report & 1 & Caselli et al, $1991^{[61]}$ \\
\hline Migraine, neuropsychiatric disease, and focal acute neurological deficits & Prospective & 48 & Escudero et al, $1995^{[62]}$ \\
\hline Cerebral manifestations (focal and diffuse) and spinal cord disease & Case series & 16 & Alexander et al, 1982 [63] \\
\hline Peripheral nervous system abnormalities & Cross-sectional & 39 & Barendregt et al, $20011^{[46]}$ \\
\hline Sensorimotor/sensory axonal polyneuropathy, spinal cord disease, and cognitive dysfunction & Prospective & 25 & Lafitte et al, $2001^{[64]}$ \\
\hline Peripheral neuropathy & Cross-sectional & 46 & Gemignani et al, $19944^{[65]}$ \\
\hline $\begin{array}{l}\text { CNS disease, mostly non-focal dysfunction; PNS disease, mostly mild or severe sensory or sensory-motor } \\
\text { polyneuropathies }\end{array}$ & Cohort & 87 & Govoni et al, $1999^{[66]}$ \\
\hline $\begin{array}{l}\text { Sensory ataxic neuropathy, painful sensory neuropathy without sensory ataxia, multiple mononeuropathy, } \\
\text { multiple cranial neuropathy, trigeminal neuropathy, autonomic neuropathy, and radiculoneuropathy }\end{array}$ & Cross-sectional & 92 & Mori et al, $2005^{[44]}$ \\
\hline Motor neuropathy, sensory neuropathy, sensorimotor neuropathy, and small-diameter nerve fiber neuropathy & Cross-sectional & 62 & Goransson et al, $2006^{[48]}$ \\
\hline $\begin{array}{l}\text { CNS disorders: spinal cord involvement, brain involvement, and optic neuropathy. PNS involvement: symmetric } \\
\text { axonal sensorimotor polyneuropathy, cranial nerve involvement affecting trigeminal, facial, or cochlear nerves. }\end{array}$ & Retrospective & 82 & Delalande et al_, $2004{ }^{[2]}$ \\
\hline $\begin{array}{l}\text { Complaints of painful distal paresthesias in the feet, abnormal sweating, and decreased pinprick sensation. Small- } \\
\text { fiber neuropathy }\end{array}$ & Cohort & 32 & Lopate et al, $2006^{[67]}$ \\
\hline Subcortical dementia & Case report & 1 & Kawashima et al, $1993^{[68]}$ \\
\hline $\begin{array}{l}\text { PNS involvement: small fiber neuropathy; trigeminal, facial, or trochlear nerves involvement; multiple } \\
\text { mononeuropathy; sensorimotor polyneuropathy; autonomic neuropathy; and myasthenia gravis. CNS } \\
\text { involvement: headache; spinal cord involvement; seizures; motor and sensory deficit; movement disorders; } \\
\text { neuromyelitis optica; aseptic meningitis. Cognitive dysfunction }\end{array}$ & $\begin{array}{l}\text { Retrospective cross- } \\
\text { sectional case-control }\end{array}$ & 93 & Teixeira et al, $2013^{[69]}$ \\
\hline $\begin{array}{l}\text { Atypical neurologicmanifestations: pseudotumoral lesion; multiple mononeuropathy; progressive multiple } \\
\text { sclerosis; and myelitis along with progressive cognitive disorders }\end{array}$ & Case series & 4 & $\underline{\text { Michel }}$ et al_, $2011^{[70]}$ \\
\hline Neuromyelitis optica & Case series & 2 & Nitescu et al, $2011^{[71]}$ \\
\hline $\begin{array}{l}\text { Peripheral neuropathy: axonal sensorimotor polyneuropathy, pure sensory neuronopathy, mononeuropathy } \\
\text { multiplex, and demyelinating polyradiculoneuropathy }\end{array}$ & Cross-sectional & 102 & Brito-Zeron et al_, $2013^{[72]}$ \\
\hline Multiple sclerosis & Case report & 1 & Liu et al, $2014{ }^{[73]}$ \\
\hline Neuropathy axonal (pure sensory or sensorimotor) & Cross-sectional & 44 & Pavlakis et al, $2011^{[74]}$ \\
\hline CNS vasculitic involvement & Case report & 1 & Hasiloglu et al, $2012^{[75]}$ \\
\hline Neuromyelitis optica & Retrospective & 43 & Qiao et al, $2015^{[55]}$ \\
\hline Autonomic dysfunction & Cohort & 154 & Koh et al , $2017^{[76]}$ \\
\hline
\end{tabular}


N: Number of study cases; CSN: Central Nervous System; PNS: Peripheral Nervous System 
This high variability of clinical manifestations of SS with different responses to treatment should be related to diverse and complex mechanisms of injury such as vasculitis and lymphocytic infiltration. Changes in the structure of the dorsal spinal cord and the dorsal ganglion roots, association with autonomic dysfunctions, decrease in the white matter, and loss of the gray matter of the hippocampal area were observed in SS patients [77-79].

\section{2.b. SS and the mechanisms of neurological manifestations}

The mechanisms triggering the neurological manifestations in SS are unclear. They involve genetic predisposition, environmental agents, trauma and posttraumatic stress, autoimmunity against the CNS and peripheral nervous systems (PNS), in addition to the neuroimmunendocrine network disruption $[47,80$ 85]. More specifically, unknown causes trigger DNA demethylation, microRNA abnormal expression, unbalance of Interferon I ( $\alpha$ and $\beta$ ) and II ( $\mathrm{Y}$ ), and anti-neuron autoantibodies production [55,83,86-88]. The 2-5 oligo-adenylate synthetase 1 (OAS1) gene defect leads to lower responsiveness to IFN- $\gamma$, and induces higher production of IFN-y causing severe complications as neuropathy in SS [85].

The increase in corneal nerve thickness and higher number of antigen presenting cells in the cornea, nerve vasculitis, nonvascular encephalitis, neuromyelitis, axonal and CNS degeneration are hypothesized to be responsible for those sensorial, autonomic, cognitive or behavioral neurological manifestations of SS $[24,47,81,89]$.

It is interesting to notice that the same structures that are altered in image exams of SS patients compared to control individuals are those where the TKP has shown to be more sensitive to handle in experimental studies, as synapses of the 
sensorial fibers, at the dorsal ganglion root, hippocampus, thalamus and LFU [2,12,13,27,39,77,90-95] (Table 2).

Table 2. Changes in the Nervous system and in the exocrine glands in Sjögren's Syndrome (SS) and after the modulation of the tryptophan/kynurenine pathway (TKP).

\begin{tabular}{|c|c|c|}
\hline Structure & Sjögren's Syndrome & Tryptophan/kynurenine pathway \\
\hline $\begin{array}{l}\text { Dorsal ganglion } \\
\text { root }\end{array}$ & $\begin{array}{l}\text { Dorsal ganglion root } \\
\text { alterations in the MRI, } \\
\text { associated with } \\
\text { increased intradermal } \\
\text { nerve fiber density in skin } \\
\text { biopsy [96] }\end{array}$ & $\begin{array}{l}\text { Sciatic injury increase kynurenine } \\
\text { monooxygenase (KMO) in the dorsal } \\
\text { ganglion root of rats [91] }\end{array}$ \\
\hline Hippocampus & $\begin{array}{l}\text { Hippocampal atrophy in } \\
\text { SS patients [27] }\end{array}$ & $\begin{array}{l}\text { IDO and kynurenine-3-hydroxylase } \\
\text { increase in the hippocampus after } \\
\text { day } 2 \text { after CNS ischemia [97]. }\end{array}$ \\
\hline $\begin{array}{l}\text { Exocrine Glands } \\
\text { and LFU }\end{array}$ & $\begin{array}{l}\text { Changes in the LG and } \\
\text { the SG in the MRI, nerve } \\
\text { changes in the cornea of } \\
\text { SS patients }[94,98]\end{array}$ & $\begin{array}{l}\text { Increase in kynurenine in salivary } \\
\text { gland after ductal ligation, LG } \\
\text { atrophy due to tryptophan } \\
\text { deprivation }[90,99]\end{array}$ \\
\hline
\end{tabular}

MRI: magnetic resonance image, SS: Sjögren's syndrome, LG: lacrimal gland,

SG: salivary gland, CNS: central nervous system, IDO: indoleamine 2,3dioxygenase

2.c. The immune and the endocrine modulation of neurological findings in SS 
The concept implicit in the neuroimmunendocrine network predicts that cellular and molecular communication among those three systems are responsible for the homeostasis of the body organs; and a disruption in this network take part in the mechanism of the diseases [100-103]. Acetyl-choline (Ach), dopamine, glutamatergic and other neurotransmitters, are also secreted by lymphocytes [104]. In the other hand, the autonomic nervous system is capable of modulating lymphocytes proliferation in target organs like spleen, liver, kidney, and brain $[23,105,106]$. In addition, the sensory neurons are capable to secrete peptides with immunomodulatory properties as galanin, netrin-1, and somatostatin and promote or attenuate inflammatory responses $[107,108]$.

Hormones, in particular the sex hormones, can modulate the inflammation and the pain, sensitizing the ionic receptors expressed in the neurons and epithelial cells, called transient receptor of potential (TRPs), and stimulating growth factors and cytokines expression in the target tissues as lacrimal and salivary glands (LG and SG), hippocampus and trigeminal ganglion of the CNS, and also on other target tissues[109-116]. Those mechanisms explain the sex hormones mediated amplification and perpetuation of the inflammatory process, the pain hypersensitivity and exocrine glands dryness manifestations in SS, where estrogen potentiate the pain and pro-inflammatory mediators and androgens work oppositely $[80,111,117-119]$. Although the trigger of the first event in SS and the steps to the chronic phase are poorly understood, there are strong clinical association between female sex hormones, and the inflammatory mediators involved in innate, and also adaptive immunity $[4,44,111,113,120,121]$ (Figure 1). 
These observations taken together indicate that hormones and neural pathways are involved in immune responses, resulting in variability in the pain sensation, inflammatory reaction, tissue integrity and functional disruption $[5,23]$. Those observations are in agreement with recent reports describing multiple comorbidities and extra glandular manifestations (EGM) in SS patients $[2,92,122]$.

The loss or damage of the nerve fibers, dorsal root ganglionitis, nerve vasculitis and reduction of the CNS matter can be observed in image exams, as magnetic resonance image (MRI) or skin biopsies in SS; they are also implicated in the mechanisms of the diseases, and work as diagnostic markers of SS $[24,77,78,96]$. For example, the cognitive impairment on SS patients are associated with antibodies against NR2 subtype of the N-metyl Aspartate receptor (anti-NR2 antibodies) in the cerebrospinal fluid (CSF) mediating hippocampal gray matter atrophy, observed by MRI [27]. In summary, the SS inflammatory activity in the PNS and CNS causes the signs and symptoms described above, and are modulated by hormones, neurotransmitters and cytokines susceptible to the TKP interference $[13,14,102]$.

\section{The tryptophan/kynurenine pathway (TKP)}

The metabolism of L-tryptophan (LTF) leads to the generation of several neuroactive compounds by the serotoninergic and the kynurenine pathways. In the serotoninergic pathway, L-tryptophan is metabolized to serotonin (5-HT), and in some cells, to melatonin. Serotonin acts as a neurotransmitter with a variety of functions on behavior and psychiatric symptoms (depression and anxiety), platelet aggregation, gastrointestinal 
tract control (satiety, secretion, and peristalsis) and tumor resistance.

Melatonin acts as a neurohormone in the circadian rhythm with also an antiinflammatory, anti-angiogenic and anti-tumoral immunomodulatory effects [123] (Figure 2).

In the catabolic TKP, the tryptophan 2,3-dioxygenase (TDO) specifically metabolizes tryptophan in the liver and responds to hormonal regulations, such as cortisol and glucagon, and to the tryptophan concentration [124] (Figure 2).

The IDO enzyme regulates both innate and adaptive immune responses through the degradation of the essential amino acid tryptophan into kynurenine and other metabolites, which suppress effector T-cell function and promote the differentiation of regulatory T cells. The IDO also metabolizes serotonin, melatonin, and tryptophan until $\mathrm{N}$-formil kynurenine and kynurenine in the lung, the brain, and blood, producing quinolinic acid and nicotinamide adenine nucleotide (NAD+) [125-127]. The TKP is responsible for $95-99 \%$ of the entire tryptophan catabolism [128] (Figure 2).

Figure 2. The tryptophan/kynurenine pathway (TKP) and their resulting metabolites. 


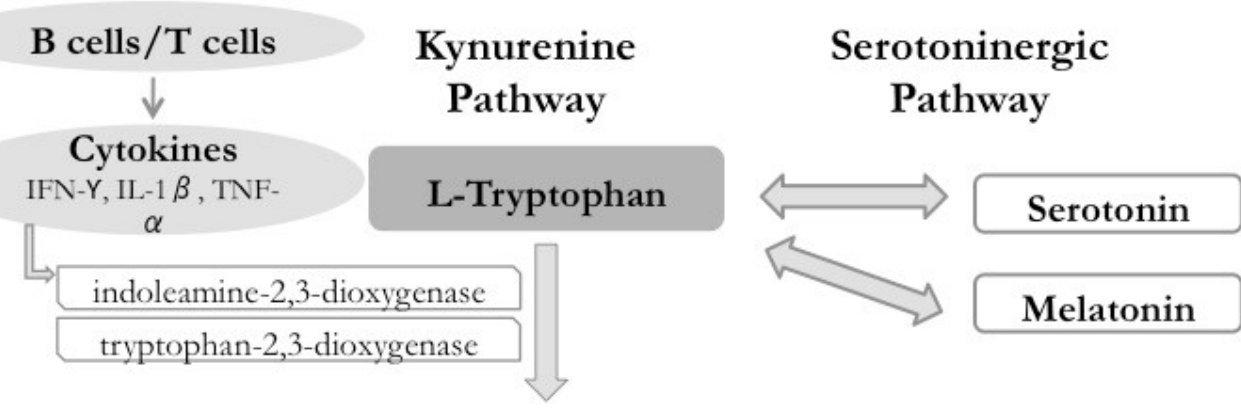

\section{$\mathrm{N}$-formylkynurenine}

formylkynurenine formidase

kynurenine-3-monooxygenase

kynurenine

Kynurenine

aminotranferase

\section{3-hydroxylkynurenine}

kynureninase

3-hydroxyanthranilic acid

3-hydroxyantrhanilic acid oxidase

Quinolinic acid

quinolinate phosphoribosyl transferase

\section{$\mathrm{NAD}^{+}$}

IDO is found mainly in immune cells, and has enzymatic activity in the cytoplasm and also transcriptional activity in the nucleus, playing a unique role as a signaling molecule, modulating immune responses [129-131]. The 
nuclear effect contributes to an enzyme "self-amplification" in an IFNdependent loop that may account for the phenotype of tolerance, attenuating or preventing immune reactions and mediating persistent pain in several conditions, including SS [129,130,132-134]. The IDO activity is induced by macrophages and by cytokines, like IFN-Y and TNF- $\alpha$, by prostaglandins, by viral and bacterial infections and by lipopolysaccharides, by dendritic cells and the sub-products of kynurenine [135-139]. IDO overexpression has been documented in patients with systemic lupus erythematosus (SLE) and SS, as well as in sepsis $[15,36,140]$. In patients who are positive for the IFN gene expression signature, Treg cell levels are elevated in combination with increased IDO activity, with tolerance and immune modulation[132]. Those regulatory $\mathrm{T}$ lymphocytes cells represent a diverse subclass of T cells, a protagonist in the maintenance of self-tolerance and immune modulation[141].

The TKP is catalyzed by the IDO enzyme and it can be induced by the cytokine IFN- $\mathrm{\gamma}$, as observed in studies with mice where IFN-y or IFN-y receptor knockout prevent kynurenine production [142]. The phenomenon is dependent on antigen-presenting cells (APCs) mentioned above, as observed in mice models with graft-versus host disease (GVHD) and induction of this TKP can extend the life-span and reduce the inflammation of the gut of the wild-type mice, but not of those IFN-y receptor knockout mice [142].

The balance between INF- $\alpha$ and IFN-y activation in the inflammatory processes, either in response to an exogenous aggression or as part of an autoimmune disease as SS can interfere in the activation of the TKP and in the resulting intensity of this inflammatory process [143-145]. The production of the IFN-y and TKP activation is also dependent on the genetic background 
and on the interaction between the T cells and other cells in the target tissues of inflammatory diseases, where the pretreatment IFN-Y can suppress the presentation of the auto antigens by those target cells [146-148].

The isoform IDO2, and also TDO1 are enzymes involved in the catabolism of the amino acid tryptophan and operate in similar ways in the immunomodulation, with variations in the target tissues, cells involved in the metabolic pathways in several conditions. However, further studies are necessary to clarify their diversity in diseases, including SS $[149,150]$.

\section{The TKP and the neurologic manifestations}

The relationship between tryptophan, serotonin, and depression has an extended history in psychiatry. The development of depressive symptoms is correlated with high levels of tryptophan metabolites in urine [37] and with a decrease of tryptophan in the blood and cerebrospinal fluid $[151,152]$. The tryptophan transport across the blood-brain barrier, specific inflammation and damage caused by brain-reactive autoantibodies and immune complexes play a critical role in the regulation of tryptophan metabolism in the brain [123]. There is substantial evidence to suggest that in addition to serotonergic neurons, other cells such as astrocytes, dendritic cells, microglia, and macrophages also synthesize multiple neuroactive metabolites via the enzyme IDO and the TKP at CNS [153]. Evidences underlying the mechanisms have come from clinical studies that examined the effects of IFN$\alpha$ on the mood of cancer and hepatitis $C$ virus-infected patients. In both, the development of depressive symptoms was associated with decreased circulating tryptophan levels and enhanced formation of kynurenine, indicating that IDO pathway is active [154-156]. 
Tryptophan metabolites generated in the TKP have been associated with neurodegenerative diseases such as acquired immunodeficiency syndrome (AIDS)-related dementia, Alzheimer's and Huntington's diseases, and neuropsychiatric diseases like bipolar disorder and schizophrenia [157,158]. The synthesis of kynurenine in the CNS is affected by dietary intake of tryptophan and by the gut microbiota, and deprivation induces depression, cognitive dysfunction (attention, memory, and execution), among other neurologic dysfunctions through the glutamatergic receptors [14,40,159-162].

Tryptophan metabolism in astrocytes leads to the production of the kynurenic acid reported to take part in neuroprotective actions. On the other hand, microglia cells give rise to metabolites with reactive oxidative properties including hydroxykynurenine and 3-hydroxyanthranilic acid and quinolinic acid which also acts as an agonist at the glutamate N-methyl-D-aspartate (NMDA) receptor subtype and may contribute to excitotoxicity and neurotoxicity [163165].

In healthy subjects, there is a well-adjusted system in the TKP by the action of kynurenines aminotransferases (KATs) towards kynurenic acid or to quinolinic acid by (KMO). Kynurenic acid, which is reported to promote neuroprotective and immunosuppressive actions in CNS, and plays a role as an NMDA antagonist, blocking this glutamatergic receptor. An enhanced IDO activity and a deviation to KMO downstream are observed by stimulation of cytokines such as IFN-y [166]. KMO has a clear inflammatory and proapoptotic drive. Its intermediate compound, quinolinic acid, acts as an agonist at NMDA receptor, modulating excitatory amino acid transmission, and may serve as neurotoxic agent implicated in the pathogenesis of several 
neurologic diseases[123,157]. Likewise, 3-hidroxikynurenine has also neurotoxic effect, probably associated with the conversion of reactive oxygen species and apoptosis [167-170]. [78]

The NR2 subtype NMDA receptor is ubiquitously distributed through the brain with a unusually high density in the hippocampus [171]. Hippocampus is a brain structure, linked to the autonomous nervous system, with critical importance for memory formation and learning, and is also affected in mood disorders and in SS [77,78,172,173]. Likewise, the NR2B subunit of NMDA receptor is widespread in dorsal root ganglion and may mediate peripheral sensitization and visceral pain [174]. Those receptors are critically involved in the initiation and maintenance of neuronal hyperexcitability after noxious events, by C-fiber stimulation [175].

In the rodent model of peripheral nerve injury, tibial and peroneal nerves of one leg were sectioned, but the sural branch nerve was left intact. After seven days, it was observed that IDO1 was activated and the kynurenine rose in the bloodstream, accompanied by the depressive behavior, confirmed by the extended time of immobility in the forced swim test and allodynia in the paw withdraw in response to mechanical stimulation with von Frey hair. Those findings were followed by an increase in the levels of $\mathrm{KMO}$, quinolinic acid, and reduce the kynureneic acid in the contralateral hippocampus, confirming the role of the hippocampal neurons as the site in the CNS for the perpetuation of the symptoms. The inhibitory effect of interleukin-1 $\beta(\mathrm{IL}-1 \beta)$ by injection of IL-1 $\beta$ receptor antagonist in the CNS ventricular space reduced the depressive behavior and KMO mRNA levels but did not change the allodynia [39]. Depression was associated with decreased 
levels of tryptophan in patients with cancer receiving therapy with IL-2 and IFN- $\alpha$, suggesting that those cytokines impact the levels of serotonin [155]. Studies observing the triggering of inflammation of the macaque CNS with poliovirus inoculation revealed that quinolinic acid, kynurenine, and other metabolites of the TKP accumulate in the spinal cord, CSF, but not as much in the bloodstream, in levels that were corresponding to the clinical manifestations of functional damage $[12,135]$. Moreover, the in vitro conversion of L-tryptophan in kynurenine by fetal neuronal cells was dependent upon IFN-y stimulation in the presence of macrophages in the culture [12].

Confirming the hippocampus as a target regulatory CNS organ in pain and depression, it was shown that chronic pain in rats exposed to social stress or paw arthritis increase the levels of IDO, and also increase the levels of kynurenine and decrease the levels of serotonin in the hippocampus [176]. This situation is similar to the observed in human plasma levels of IDO, kynurenine/tryptophan and serotonin/tryptophan levels in patients with back pain and depression, where the first two rise and the third one decreases, as revealed in the same paper. Moreover, the IDO1 knockout mice presented lower nociceptive and depressive behavior compared to the wild type, and this behavior was not attenuated in the wild type that received an intraperitoneal injection of the NSAID acetaminophen, suggesting that this behavior is not dependent of the inflammatory mechanisms alone. Furthermore, the authors found that IL-6 is overexpressed in rats with arthritis and the Jak2/Stat3 signaling pathway activated in the blood and the hippocampus of rats with depressive and nocioceptive behavior. The injection of IL-6 anti-serum attenuated the allodynia and hyperestesia in those animal models. In Neuro2a 
cells (a mice neuroblastoma cell line) in culture, the incubation with IL-6 induced increase in IDO1 mRNA and protein [176].

Therefore, persistent pain with allodynia and hyperalgesia has a central component (spinal and supraspinal cord), supporting the involvement of glutamatergicneurotransmission, associated with TKP signaling in the clinical manifestations and the role of the hippocampus as a criticalorgan in this process and the TKP in their physiopathology $[9,16,28,176,177]$. Those facts allow us to exam the relationship among TKP, neurologic manifestations and autoimmune diseases like SS.

\section{4.a. The role of the hippocampus in the TKP of the neurologic manifestations}

Despite the agreement among clinical studies on changes in the TKP and SS, it is admissible that the lack of association between the symptoms of depression and fatigue in SS and the changes in the TKP is due to difficulties to monitor the changes in the CNS, more specifically in the hippocampus $[43,132,178,179]$

Not only SS patients but also individuals exposed to chronic stress present signs of hippocampal structure and NMDA signaling changes $[27,180]$. Animal models studies reveal that the hippocampus initially adapts to early, high and frequent stress, but the persistence of the aggression rise the levels of glutamate and disrupt the hormonal and neurotransmitters control, leading to a NMDA driven neuronal death and hippocampus atrophy $[181,182]$.

Moreover, hypothalamus-pituitary-adrenal activity has a modulatory effect on those events and the female sex hormone estrogen increase the 
synaptic connections and the expression of Nerve Growth Factor (NGF) in the hippocampus, supporting the hormone influence and the increased symptoms and pain sensitivity in the females with SS $[111,114,181,183]$.

The cytokines, like IFN- $\gamma$, IL-1, TNF- $\alpha$ increase the kynurenine expression, from the tryptophan by the IDO enzyme, deviating this amino acid form the production of serotonin in the CNS [13]. The resulted imbalance between the kynurenine metabolites and serotonin production in the hippocampus induce depression, slow reactions and other cognitive disorders [184]. The target cells are microglial cells, astrocytes and other inflammatory cells present in the hippocampus and other CNS areas [19]. Once impacted by those cytokines, the cells reduce the glutamate re-uptake, increase the glutamatergic signaling, reduce the capacity to produce serotonin, trigger the nociceptive and depressive behavior, induce cells death (mostly the astrocytes) prolonging the inflammatory effect $[13,19,28,39,185]$.

It is interesting to note that serotonin works as a modulator of the glutamate actions. The PNS sensory transmission has silent glutamate synapses that are activated by serotonin. Once those silent synapses are serotonin-activated, they amplify the peripheral nociceptive glutamate signaling through the NMDA or AMPA receptors from the spinal dorsal horn to the CNS [186,187]. In the CNS, the glutamate/serotonin co-neurotransmission are extensively studied, including in the hippocampus. The five sub-types of serotonergic receptors are expressed in different combinations among several cells, antagonizing the glutamatergic NMDA receptors at different levels, from preventing cells glutamate release to competing for the same intracellular signaling pathways in the hippocampus but not in other brain tissues [188-193]. 
Also, to demonstrate the differences among the TKP activity in the CNS and in other parts of the body, the systemic treatment with dexamethasone to reduce the inflammation induced by lipopolysaccharide intraperitoneal injection (LPS) promoted a decrease of IDO enzymes in peripheral tissues (lung, spleen and liver) but an increase in the brain microglial cells and astrocytes [185,194]. Moreover, the use of systemic subcutaneous slow-release corticosteroid pellets in rats increased the levels of NR2 NMDA glutamatergic receptors mRNA in the hippocampus [195]. Those observations suggest that corticosteroid treatment, used to reduce chronic inflammation may potentiate the nociceptive and depressive behavior in the long-term.

Also, it was shown in HIV-infected patients, that quinolinic acid (the metabolite of the kynurenine, that mimics the glutamate in NMDA receptors), is several times higher in the brain, than in the cerebrospinal fluid or in the blood [196].

Taken together, these information locate the hippocampus as a primary responsible for nociception and mood control, also a site where the rise in TKP activity increases in response to inflammation, and its metabolites (i.e., quinolinic acid and glutamate) induce manifestation of pain and depressive behavior, which can be amplified by serotonin waking up of extra peripheral silent glutamatergic synapses. Moreover, in the chronic inflammations, like the SS, the levels of serotonin in the CNS are diminished by tryptophan consumption throughout the TKP. The attempt to revert the inflammation with corticosteroids, is not achieved in the CNS as it occurs in other target organs and ends up with the death of microglial cells, astrocytes and neurons, mostly 
the hippocampus and the dorsal ganglion root $[185,194,197]$. These observations support the possible mechanisms of SS neurologic manifestations and the TKP (Figure 3).

Figure 3. The tryptophan/kynurenine pathway (TKP) and its implications in the Sjögren's syndrome physiopathology.

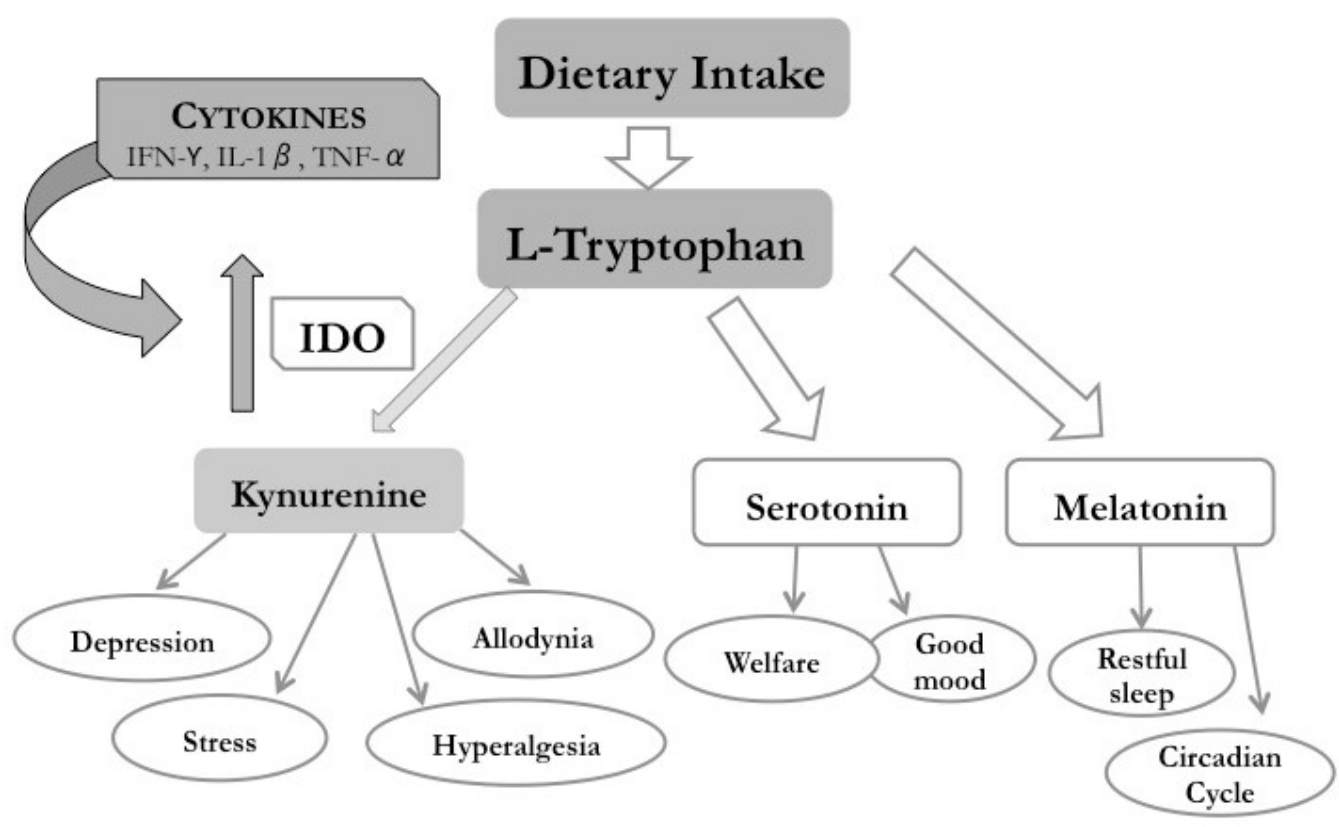

\section{The TKP and the neuropathy in SS}

Decades ago, reports revealed that the ingestion of L-5-

Hydroxytryptophan induced signs and symptoms similar to scleroderma, with high plasma levels of kynurenine [198]. Moreover, excessive doses of tryptophan (upper than $1.2 \mathrm{~g} /$ day) triggered eosinophilia, severe muscular weakness and pain, and oral ulcers, with rise of the hepatic enzymes aspartate and alanine aminotransferase (ASA and ALA), in addition to inflammatory infiltrate in various organs [161]. Those events were associated with high plasma levels of kynurenine as observed in cases with scleroderma and SS [140,198]. 
Salivary gland (SG) ductal ligation in rats induces tissue suffering and atrophy and increase in the systemic levels of kynurenine (as measured in the hair) and was associated not just with salivary hypofunction but also with body weight loss, along of the six months of the experimental period. It indicates that higher levels of plasma kynurenine can reflect a peripheral organ suffering but also that SG damage is sufficient to impact the whole body metabolism as shown by the body weight loss compared to controls [99].

Those observations sound otherwise to the hypothesis for the neuropathic pain combined with less EGM profile for a subgroup of SS patients driven by the TKP, presented in session 2; and the anti-inflammatory and immune tolerance effects of the TKP introduced in session $3 \mathrm{~b}$, in models of GVHD, viral infection, tumors or chemical challenges. However, it is necessary to understand the role of different triggers on each target organ, the individual capacity to metabolize and eliminate the side products of the TKP and those events along of the time course of the disease, including the influence of distinct therapeutic strategies.

As mentioned above, the tryptophan levels in the body are dependent on dietary intake, however, the influence in the serotonin conversion is limited to about $10 \%$ of the total intake, due to the hemato-encephalic barrier and other environmental stimuli, but also the individual metabolic conditions given by the genetic background [37,159-161,199-201]. For example, when female C57 ovariectomized mice ingest bisphenol A (BPA), an environmental contaminant with endocrine disruption capacity, it causes bowel inflammation and reduction in the levels of tryptophan and serotonin, indicating that 
environmental contaminants and the intestinal microbiota affect the TKP in the chronic inflammatory diseases [160].

The flow cytometric analysis of peripheral blood revealed a higher expression of IDO in dendritic cells of pSS patients, and in each of the subgroups, classified either by the presence of clinical or serological activity or none of those, compared to dendritic cells of healthy controls, and those findings were associated with immune regulation by IFN- $\alpha$ [202].

The measurement of the median expression of IDO in antigen presenting cells (APCs) and in T cells were higher in peripheral blood cells of pSS patients than in controls, matched by age and sex, using also specific antibodies and flow cytometry, despite of the heterogeneity of the groups and the high internal variability of the results [203]. Therefore, the T cell mediated autoimmune activity present in autoimmune diseases, including SLE and SS have been associated with higher activity of the TKP, although their effects on auto antigen stimulation and the IFN-y activity is unknown [202,203].

Different profiles regarding IFN-y activity were identified in the pSS population, in addition to 55 genes and 19 metabolic pathways were distinctly identified in a subset of pSS patients with fatigue [204,205]. Higher IDO activity was observed in IFN-ץ positive pSS patients, with higher levels of IDO mRNA and IFN-y mRNA in circulating monocytes, and those observations were associated with the up-regulation of apoptotic and neurotoxic downstream steps in the TKP [132]. The levels of the serum tryptophan are higher in healthy than in primary SS women (pSS). On the other hand, the kynurenine levels and the kynurenine/tryptophan ratio are more elevated in pSS than in healthy women and patients with sicca non-SS. Those observations were also 
present in pSS men, confirming a higher activity of the IDO enzyme in the TKP $[140,206]$. Moreover, the higher levels of kynurenine were associated with higher levels of inflammatory markers in the serum, as erythrocyte sedimentation rate, c-reactive protein, creatinine, $\lg \mathrm{A}, \beta-2$ microglobulin and positivity to anti-nuclear antibody. Higher levels of kynurenine was also associated with a lower proportion of individuals on corticosteroid usage but not with the frequency of neurologic manifestations in the pSS group $[140,206]$. In another recent study, polyneuropathy combines with more frequent positivity for the autoantibodies anti-Ro (SSa) and anti-La (SSb) in pSS [42]. Taken together, these studies suggest that TKP higher activity is related to clinical and laboratory signs of systemic inflammation, which may disagree with our hypothesis but also can indicate that those studies documented a midway between the pain/neuropathic and the inflammatory poles of the disease $[140,206,207]$. Although the association of neurological or laboratory findings and kynurenine metabolites is evident in those studies, the cause/effect relationship between the metabolites of the TKP and these manifestations is still unclear.

In another study, an association of fibromyalgia, and other psychological symptoms, as anxiety, depression, insomnia, psychoticism and neuroticism with fatigue were observed in a large series of pSS patients with 106 cases, where 32 were fatigued and 74 non fatigued, identified by the Functional Assessment of Chronic IIIness Therapy-Fatigue (FACIT-F) scale, with a cut-off of 30 on a scale ranging from 0 to 52 . However the measurement of the IDO mRNA in peripheral blood leukocytes was not different between pSS patients with and without fatigue [178]. In addition, no 
other clinical or laboratorial association was identified, except for the number of individuals using hydro chloroquine, which were $50 \%$ among the pSS fatigue group and $28 \%$ in the pSS non-fatigue group. On the other hand, it was observed a higher expression of IDO-1 mRNA levels associated with plasma levels of IFN-Y [178].

Fatigue was associated with higher levels of TKP activity in SLE patients, but only on those with clinical activity of the disease measured by the Systemic Lupus Erythematous Disease Activity Index (SLEDAI) with the score above five, which may confirms the possibility that the TKP is overexpressed when challenged by higher inflammatory activity [36]. Moreover, the levels of serum tryptophan are lower in SLE than in controls, scleroderma and pSS patients, who may reflect the higher activity and broad manifestations of the disease, compared to the other two conditions (i.e., pSS and SSc) that are more tissue-specific than SLE [179]. Experimental studies mimic the clinical findings of cognitive impairment, but not of depression, associated with microglia and astrocyte activation in the hippocampus of SLE mice models induced by the injection of anti-ribosomal antibodies in the CNS, compared to controls [208]. Unfortunately, the TKP was not investigated in that study.

The failure to present a more conclusive association between the TKP, as a marker of the neurologic manifestations in SS may be due to: a) the heterogeneity of the cases, b) the lack of a healthy control group in some studies, c) the possible dissociation between the levels TKP activity in the blood and the biochemical changes in the CNS tissues, specially the hippocampus, d) a higher TKP activity takes place in response to the inflammatory activity but persists only on those target organs (e.g.; 
hippocampus and dorsal ganglion root) after the inflammatory control. Those pitfalls must be taken into consideration in future studies addressing the present hypothesis of the association between SS neurologic features and TKP.

\section{Therapy to modulate the TKP}

The overexpression of IFN-y, the induction of pro-inflammatorygenes, as TNF- $\alpha$, interleukins, BAFF, promoting the activation of B cells and the rise of autoantibodies in the blood are involved in the physiopathology of SS $[84,143,209-213]$. Therefore, the therapeutic strategies to treat SS include immune modulators and biological therapy to refrain B and T cells activity and proliferation [214-217]. The limitations of those strategies open opportunities for new procedures and complementary therapies. Among the several possibilities, the potential modulation of the TKP has been explored in SS, as in other autoimmune diseases, including rheumatoid arthritis, SLE, systemic sclerosis, despite of the uncertainties in the influence of this pathway in the mechanisms, as pointed in session $5[15,218]$ (Table 3). 
Table 3. List of studies showing potentials therapeutic strategies to modulate pain and inflammation targeting the therapeutic interventions in the kynurenine pathway

Description of the therapeutic interventions in the kynurenine pathway

Administration of inhibitor of kynureninase (mNBA and oMBA) increased the content of kynurenine and KYNA in the brain, blood

liver, and kidney following. There was a decrease in locomotor activity and protection of audiogenic seizures

m-NBA administration significantly increased the concentration of kynurenine and kynurenate in the brain, blood, and in the liver.

This increase is associated with sedative and anticonvulsant actions, suggesting a functional antagonism of the excitatory amino

acid receptors

Administration of sulfur-containing amino acids, L-cysteine sulphinate, L-cysteate, L-homocysteine sulphinate and L-

homocysteate reduced KYNA production and inhibited the activity of KAT I and / or KAT II

$\mathrm{N}(\mathrm{G})$-nitro-L-arginine and its methyl ester impair brain synthesis of kynurenic acid, probably via NO-independent mechanism,

what could contribute, to the enhancement of neurotoxicity or seizures observed in some experimental designs based on their

use

Activation of the PGC-1 $\alpha 1-P P A R \alpha / \delta$ pathway increases skeletal muscle expression of kynurenine aminotransferases, thus

enhancing the conversion of kynurenine into kynurenic acid. Reducing plasma kynurenine protects the brain from stress-induced

changes associated with depression

KYNA was an important early mediator of leukocyte recruitment in an in vitro vascular flow model

In an EAE, IDO activity was increased in the spleen during the preclinical phase, and within the brain and spinal cord at the onset

of symptoms. Macrophages / activated microglia expressing IDO during EAE and IDO induction in microglia upon IFN-gamma

treatment with synergistic effects of TNF-alpha. Inhibition of IDO by systemic administration of 1-Mt at clinical onset significantly exacerbated disease scores

The expression and activity of KMO significantly increased in the spinal cord in an EAE. The spinal cord content of 3-HK and

quinolinic acid reached neurotoxic levels. Systemic administration of Ro 61-8048, a selective KMO inhibitor, reduced the increase

of both 3-HK and quinolinic acid, and caused accumulation of KYNA

QUIN levels were significantly elevated in the more caudal regions of the spinal cords of animals with EAE. The initial elevation in

QUIN occurred before the appearance of behavioral signs. Last, treatment with the glucocorticoid dexamethasone prevented

both the signs of EAE and the elevation in spinal cord QUIN.

The NMDA receptor antagonist memantine to modify the neurological course of EAE. Significantly restored BBB integrity,

reduced symptoms, and limited inflammatory lesions

In neuropathy, after $\mathrm{CCl}$ had an increase in the KMO mRNA levels in the spinal cord and the DRG) that were reduced by chronic

administration of the microglial inhibitor minocycline. There was a decrease in the intensity of neuropathy. KMO inhibitors (Ro61-

Study mode

Experimental study in rats

Experimental study in rats

Experimental study in rats

Experimental study in rats

Author, year

Chiarugi et al, 1995 [219]

Carpenedo et al,

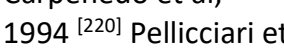

al, $1994^{\text {[221] }}$

Kocki et al, $2003^{\text {[222] }}$

Luchowski et al, 2001

[223]

Experimental study in rats

Agudelo et al, 2014

[224]

In vitro human study

Experimental study in rats

Barth et al, $2009^{\text {[225] }}$

Kwidzinski et al, 2005 [226]

Experimental study in rats

Chiarugi et al, $2001^{[227]}$

Experimental study in rats

Flanagan et al, 1995 [228]

Experimental study in rats

Paul et al, $2002^{[229]}$

Experimental study in rats

Rojewska et al, 2016 [91]

6048 ) administration potentiated the analgesic properties of morphine 
Chronic pain induced depressive behavior and IDO1 upregulation in the bilateral hippocampus. Upregulation of IDO1 resulted in the increased kynurenine/tryptophan ratio and decreased serotonin/tryptophan ratio in the bilateral hippocampus. IOD1 gene knockout or pharmacological inhibition of hippocampal IDO1 activity attenuated both nociceptive and depressive behavior

mNBA: m-nitrobenzoylalanine; oMBA: o-methoxybenzoylalanine; KYNA: Kynurenic acid; KAT I/II: kynurenine aminotransferase I/II; NO: nitric oxide IDO: indolamine 2,3dioxygenase; EAE: experimental autoimmune encephalomyelitis; 1-Mt: 1-methyl-tryptophan; KMO: kynurenine 3-monooxygenase; 3-HK: 3-Hydroxykynurenine; QUIN: Quinolinic acid; NMDA: N-methyl-D-aspartate; BBB: blood-brain barrier; CCI: after chronic constriction injury ; DRG: dorsal root ganglia; IDO1: indoleamine 2,3dioxygenase 
Considering the broad spectrum of substrates, target tissues, and alternative ways of the TKP, the therapeutic strategies explore interference in different steps, observing one or more of the following outcomes: attenuate inflammation, reduce chronic pain or improve fatigue and depressive feelings in SS $[132,203,218]$.

The traditional non-steroidal anti-inflammatory drugs (NSAID), acetylsalicylic acid (ASA or aspirin) and sodium diclofenac were investigated $[230,231]$. In rats, the systemic intraperitoneal injection of tryptophan alone was able to increase the kynurenine levels in the blood and the liver between 20 and 120 min. However, after combined injection of subcutaneous diclofenac with intraperitoneal tryptophan, the concentration of kynurenine increased, not just in the plasma and the liver, but also in the spinal cord and the brain, with a remarkable increase in the kidney, after 60 and $120 \mathrm{~min}$. Therefore, diclofenac disturbs the renal clearance of TKP metabolites, which may amplify the anti-inflammatory and the excitatory stimuli on nociceptive NMDA receptors, independently of the prostaglandins analgesic effects [231]. In an opposite way, a study using human peripheral blood mononuclear cells (PBMCs) revealed that aspirin, at the dose of $5 \mathrm{mM}$, incubated for three days or 2 hours, reduced the tryptophan metabolism and kynurenine production on those human PBMCs, stimulated by Concanavalin A and pokeweed mitogen (PKM), suggesting an inhibitory effect on IFN- $\gamma$, based on those triggers mechanisms of action [230]. These observations indicate that NSAID works aside of their known effects on the cycloxygenase/prostaglandins pathway, and the impact on the TKP can be diverse depending on the cell type and the specific NSAID [15]. It is also interesting to note that Aspirin, a longer and 
broadly used analgesic drug, have well known positive effects on dry eye symptoms and LG dysfunction, critical elements on the manifestations of SS [232-234].

In an in vitro study, using samples of T cells from 68 SS patients, the co-culture with mesenchymal stem umbilical cells revealed the suppression of proliferation and activation of these T circulating follicular helper cells, associated with enhanced expression and enzymatic activity of IDO, measured by RT-PCR and HPLC, respectively [235]. Another study using human complementarity determining region 1 (hCDR1), a tolerogenic peptide complementary to the human anti-DNA monoclonal antibody has shown to reduce the expression of inflammatory cytokines, downregulate the proliferation and activity of B cells, and increase the expression of antiinflammatory cytokines in rodent models of SLE [218]. In mature leukocytes of 16 SS individuals, in culture, it was shown that hCDR1 reduces the expression of inflammatory cytokines, including IFN- $y$, and increase the expression of anti-inflammatory cytokines, up-regulatingthe IDO gene expression. However, in the presence of $1 \mathrm{mT}$, an IDO inhibitor, the effect of hCDR1 on the T cell regulator cytokine FOXP3 gene expression is reduced, suggesting that the immune modulatory effect of hCDR1 is partially associated with its action over the IDO [218].

The suppression of the TKP by inhibiting the KMO can reduce the pain triggered by LPS injection in the dorsal ganglion root in rodents. It was demonstrated by systemic administration of the antibiotic minocycline or by the local administration of inhibitors of KMO [91]. They reduced the local levels of pro-inflammatorycytokines in the dorsal ganglion root and the spinal cord 
and decreased the pain and the protein expression of the following inflammatory mediators IBA-1, IL-6, IL-1 $\beta$ and NOS2 [91].

Considering the strategy to overload the TKP to modulate the pain sensation, rats were subject to systemic administration of L-4chlorokynurenine [236]. The experiments revealed that L-4-chlorokynurenine, a NMDA/glutamate receptor antagonist, given by intraperitoneal injection reached the CNS and attenuated the hyperalgesia in four models of pain and behavior response (general behavioral, formalin plantar injection, Carrageenan model and Chung neuropathy) compared to controls, MK-801 and gabapentin [236].

GVHD individuals, non-responders to corticosteroids, presented clinical improvement in the skin inflammation in a proportion of 12 out of the 20 patients with human chorionic gonadotropin (hCG) [237]. They also had a significant increase in the IDO mRNA expression in the PBMCs, and in the IL10 expression in the blood serum [237]. The thought mechanism of action was to stimulate the IDO mediated immunotolerance, similar to the mother/fetus coexistence [130].

Although useful in the conception and to revert the immune-mediated diseases, the TKP may be deleterious in neoplastic diseases, where it can allow the tumor growth, by inducing IFN secretion and, once activating IDO, suppressing the immune response against the tumor [238]. Following this concept, the first human clinical trial aimed to block the TKP and works as an anti-cancer therapy was recently published [239]. The study investigated whether, Epacadostat, an IDO inhibitor, given orally, would be well tolerated and capable of slowing the growth of tumors in 52 refractory cancer patients, 
by removing the immune tolerance against those tumors. The drug, at doses of $200 \mathrm{mg} / \mathrm{day}$, reduced the kynurenine plasma levels, indicating the reduction in the tryptophan degradation. The mean treatment time was 52 (from 7 to 284) days, and the daily doses ranged from 43 to $1400 \mathrm{mg}$. The side effects included fatigue, nausea, and pain, among others. However, no plasma changes on C-reactive protein or in the levels of the interleukins tested were observed [239]. Further conclusions are limited due to the small number and heterogeneity of the clinical cases.

Therefore, the observations of the present data on interventions in the TKP shows that it has a double direction avenue, where the inhibition at specific steps as KMO activity and quinolinic acid formation has beneficial effects on neuropathic pain and neurodegenerative disorders. On the other hand, enhancing the activity of IDO, what ultimately is capable of inhibiting pro-inflammatory cytokines and reducing the inflammatory process. How, and at which step those events can find a conciliatory mechanism to diminish the chronic pain and neurologic symptoms of SS patients but also prevent the chronic inflammatory reactions will be subject of further investigation.

\section{Future perspectives}

IFN-y triggers the deviation of the tryptophan to the TKP pathway in SS, possibly contributing to depression and pain through its action on particular organs, like the hippocampus. However, this signaling pathway is relevant to interrupt the vicious cycle of the inflammation and chronic damage of the involved tissues structure and function, including the PNS, CNS, SG, joints and the LFU. Suppression of the APCs and production of anti-inflammatory cytokines in the exocrine glands and other target tissues are the potential 
benefits of the TKP actions. Therefore, IDO and kynurenine metabolites higher expression in SS indicates so far a reactive process to modulate the large, redundant and competitive mechanism of inflammation induced by other pathways. Better ways to access the CNS and PNS organs by imaging analysis and to monitor the local activity of the TKP in SS involved organs, either glandular or not, would allow increase insights about the physiopathology of this signaling pathway in SS, how it interferes with exocrine secretion and the strategies to improve it. More effective treatments and enhanced quality of life for SS patients will be the potential benefits from this knowledge.

\section{Conclusions}

The glandular and EGM of SS are not exclusively inflammatory, but also involves a neuroimmunendocrine network, where the TKP takes part. The activity of the TKP is hard to track because of the delicate methods to trace the metabolites of this pathway in the CNS. A better understanding of this relationship between the SS physiopathology and the TKP in the CNS and the target tissues may help to clarify the discrepancies among signs and symptoms and the neurological manifestations. This knowledge can improve the therapy for SS.

\section{Figure and Tables Legends}

Box 1. Summary of evidences linking Sjögren's syndrome (SS) and the tryptophan/kynurenine signaling pathway (TKP). 
Table 1. Neurologic manifestations of Sjögren's syndrome (SS) showing the study design, number of patients involved and clinical changes observed.

Table 2. Central nervous system (CNS) structures altered in SS and sensitive to tryptophan/kynurenine pathway (TKP) modulation

Table 3. Potential therapeutic strategies to modulate pain and inflammation targeting the tryptophan/kynurenine pathway (TKP).

Figure 1. A schematic model, showing the interrelationships among the autonomic nervous system dysfunction, pathological pain and chronic inflammation in Sjögren's syndrome (SS).

Figure 2. The tryptophan/kynurenine pathway (TKP) and their resulting metabolites.

Figure 3. The tryptophan/kynurenine pathway (TKP) and its implications in the Sjögren's syndrome physiopathology. 
Box 1. Summary of evidences linking Sjögren's syndrome and the tryptophan /kynurenine pathway (TKP).

- Association among chronic inflammation, pain and neuropathic disorders

- Triggered by Interferon

- Modulated by sex hormones

- Tryptophan deprivation induces dry eye

- Sjögren's syndrome and salivary gland aggression leads to increased expression of kynurenine 


\section{Back Matter}

- Supplementary Materials: not applicable

- Acknowledgments: The authors would like to acknowledge the following

- Author Contributions: Conceptualization: Fabíola Reis de Oliveira, Valeria Valim, Thiago Mattar Cunha and Eduardo Melani Rocha; Methodology: Fabíola Reis de Oliveira, Valeria Valim and Eduardo Melani Rocha; Formal Analysis: Marina Zilio Fantucci, Fabíola Reis de Oliveira, Thiago Mattar Cunha and Eduardo Melani Rocha; Investigation: Leidiane Adriano, Marina Zilio Fantucci, Fabíola Reis de Oliveira, Thiago Mattar Cunha and Eduardo Melani Rocha; Resources: Thiago Mattar Cunha, Eduardo Melani Rocha; Data Curation: Fabíola Reis de Oliveira, Thiago Mattar Cunha, Valeria Valim and Eduardo Melani Rocha; Writing - Original Draft Preparation: Fabíola Reis de Oliveira and Eduardo Melani Rocha; Writing - Review \& Editing: Fabíola Reis de Oliveira, Valeria Valim, Leidiane Adriano, Marina Zilio Fantucci, Thiago Mattar Cunha and Eduardo Melani Rocha; Project Administration, Eduardo Melani Rocha; Funding Acquisition: Thiago Mattar Cunha and Eduardo Melani Rocha.

Conflicts of Interest: The authors declare no conflict of interest. 


\section{References}

1. Vitali, C.; Bombardieri, S.; Jonsson, R.; Moutsopoulos, H.; Alexander, E.; Carsons, S.; Daniels, T.; Fox, P.; Fox, R.; Kassan, S., et al. Classification criteria for Sjögren's syndrome: a revised version of the European criteria proposed by the American-European Consensus Group. Ann Rheum Dis 2002, 61, 554-558.

2. Delalande, S.; de Seze, J.; Fauchais, A.L.; Hachulla, E.; Stojkovic, T.; Ferriby, D.; Dubucquoi, S.; Pruvo, J.P.; Vermersch, P.; Hatron, P.Y. Neurologic manifestations in primary Sjogren syndrome: a study of 82 patients. Medicine 2004, 83, 280-291.

3. Humphreys-Beher, M.G.; Brayer, J.; Yamachika, S.; Peck, A.B.; Jonsson, R. An alternative perspective to the immune response in autoimmune exocrinopathy: induction of functional quiescence rather than destructive autoaggression. Scand J Immunol 1999, 49, 7-10.

4. Hayashi, T. Dysfunction of lacrimal and salivary glands in Sjögren's syndrome: nonimmunologic injury in preinflammatory phase and mouse model. J Biomed Biotechnol 2011, 2011, 407031, doi:10.1155/2011/407031.

5. van Bijsterveld, O.P.; Kruize, A.A.; Bleys, R.L. Central nervous system mechanisms in Sjogren's syndrome. Br J Ophthalmol 2003, 87, 128130.

6. Seror, R.; Ravaud, P.; Bowman, S.J.; Baron, G.; Tzioufas, A.; Theander, E.; Gottenberg, J.E.; Bootsma, H.; Mariette, X.; Vitali, C., et al. EULAR Sjogren's syndrome disease activity index: development of 
a consensus systemic disease activity index for primary Sjogren's syndrome. Ann Rheum Dis 2010, 69, 1103-1109, doi:10.1136/ard.2009.110619.

7. Murube, J. The first definition of Sjogren's syndrome. Ocul Surf 2010, 8, 101-110.

8. Ramos-Casals, M.; Brito-Zeron, P.; Seror, R.; Bootsma, H.; Bowman, S.J.; Dorner, T.; Gottenberg, J.E.; Mariette, X.; Theander, E.; Bombardieri, S., et al. Characterization of systemic disease in primary Sjogren's syndrome: EULAR-SS Task Force recommendations for articular, cutaneous, pulmonary and renal involvements. Rheumatology (Oxford, England) 2015, 54, 2230-2238,

doi:10.1093/rheumatology/kev200.

9. Koh, J.H.; Kwok, S.K.; Lee, J.; Son, C.N.; Kim, J.M.; Kim, H.O.; Park, S.H.; Sung, Y.K.; Choe, J.Y.; Lee, S.S., et al. Pain, xerostomia, and younger age are major determinants of fatigue in Korean patients with primary Sjogren's syndrome: a cohort study. Scand J Rheumatol 2017, 46, 49-55, doi:10.3109/03009742.2016.1153142.

10. Brito-Zeron, P.; Theander, E.; Baldini, C.; Seror, R.; Retamozo, S.; Quartuccio, L.; Bootsma, H.; Bowman, S.J.; Dorner, T.; Gottenberg, J.E., et al. Early diagnosis of primary Sjogren's syndrome: EULAR-SS task force clinical recommendations. Expert Rev Clin Immunol 2016, 12, 137-156, doi:10.1586/1744666X.2016.1109449.

11. Seara, F.A.C.; Maciel, L.; Barbosa, R.A.Q.; Rodrigues, N.C.; Silveira, A.L.B.; Marassi, M.P.; Carvalho, A.B.; Nascimento, J.H.M.; Olivares, E.L. Cardiac ischemia/reperfusion injury is inversely affected by thyroid 
hormones excess or deficiency in male Wistar rats. PLoS One 2018, 13, e0190355, doi:10.1371/journal.pone.0190355.

12. Saito, K.; Nowak, T.S., Jr.; Markey, S.P.; Heyes, M.P. Mechanism of delayed increases in kynurenine pathway metabolism in damaged brain regions following transient cerebral ischemia. J Neurochem 1993, 60, 180-192.

13. Muller, N.; Schwarz, M.J. The immune-mediated alteration of serotonin and glutamate: towards an integrated view of depression. Mol Psychiatry 2007, 12, 988-1000, doi:10.1038/sj.mp.4002006.

14. Vecsei, L.; Szalardy, L.; Fulop, F.; Toldi, J. Kynurenines in the CNS: recent advances and new questions. Nature reviews 2013, 12, 64-82, doi:10.1038/nrd3793.

15. Filippini, P.; Del Papa, N.; Sambataro, D.; Del Bufalo, A.; Locatelli, F.; Rutella, S. Emerging concepts on inhibitors of indoleamine 2,3dioxygenase in rheumatic diseases. Curr Med Chem 2012, 19, 53815393.

16. Rosenthal, P.; Borsook, D. The corneal pain system. Part I: the missing piece of the dry eye puzzle. Ocul Surf 2012, 10, 2-14, doi:10.1016/j.jtos.2012.01.002.

17. Gur, A.; Oktayoglu, P. Central nervous system abnormalities in fibromyalgia and chronic fatigue syndrome: new concepts in treatment. Curr Pharm Des 2008, 14, 1274-1294.

18. Rosenthal, P.; Baran, I.; Jacobs, D.S. Corneal pain without stain: is it real? Ocul Surf 2009, 7, 28-40. 
19. Fasick, V.; Spengler, R.N.; Samankan, S.; Nader, N.D.; Ignatowski, T.A. The hippocampus and TNF: Common links between chronic pain and depression. Neurosci Biobehav Rev 2015, 53, 139-159, doi:10.1016/j.neubiorev.2015.03.014.

20. Tracey, K.J. Physiology and immunology of the cholinergic antiinflammatory pathway. J Clin Invest 2007, 117, 289-296.

21. Lockwood, A.; Hope-Ross, M.; Chell, P. Neurotrophic keratopathy and diabetes mellitus. Eye 2006, 20, 837-839.

22. Partanen, J.; Niskanen, L.; Lehtinen, J.; Mervaala, E.; Siitonen, O.; Uusitupa, M. Natural history of peripheral neuropathy in patients with non-insulin-dependent diabetes mellitus. N Engl J Med 1995, 333, 8994, doi:10.1056/NEJM199507133330203.

23. Pavlov, V.A.; Tracey, K.J. Neural regulation of immunity: molecular mechanisms and clinical translation. Nature neuroscience 2017, 20, 156-166, doi:10.1038/nn.4477.

24. Tuisku, I.S.; Konttinen, Y.T.; Konttinen, L.M.; Tervo, T.M. Alterations in corneal sensitivity and nerve morphology in patients with primary Sjogren's syndrome. Exp Eye Res 2008, 86, 879-885, doi:10.1016/j.exer.2008.03.002.

25. Nguyen, D.H.; Vadlamudi, V.; Toshida, H.; Beuerman, R.W. Loss of parasympathetic innervation leads to sustained expression of proinflammatory genes in the rat lacrimal gland. Auton Neurosci 2006, 124, 81-89. 
26. Stern, M.E.; Gao, J.; Siemasko, K.F.; Beuerman, R.W.; Pflugfelder, S.C. The role of the lacrimal functional unit in the pathophysiology of dry eye. Exp Eye Res 2004, 78, 409-416.

27. Lauvsnes, M.B.; Beyer, M.K.; Kvaloy, J.T.; Greve, O.J.; Appenzeller, S.; Kvivik, I.; Harboe, E.; Tjensvoll, A.B.; Goransson, L.G.; Omdal, R. Association of hippocampal atrophy with cerebrospinal fluid antibodies against the NR2 subtype of the N-methyl-D-aspartate receptor in patients with systemic lupus erythematosus and patients with primary Sjogren's syndrome. Arthritis Rheumatol 2014, 66, 3387-3394, doi:10.1002/art.38852.

28. Levite, M. Glutamate receptor antibodies in neurological diseases: antiAMPA-GluR3 antibodies, anti-NMDA-NR1 antibodies, anti-NMDANR2A/B antibodies, anti-mGluR1 antibodies or anti-mGluR5 antibodies are present in subpopulations of patients with either: epilepsy, encephalitis, cerebellar ataxia, systemic lupus erythematosus (SLE) and neuropsychiatric SLE, Sjogren's syndrome, schizophrenia, mania or stroke. These autoimmune anti-glutamate receptor antibodies can bind neurons in few brain regions, activate glutamate receptors, decrease glutamate receptor's expression, impair glutamate-induced signaling and function, activate blood brain barrier endothelial cells, kill neurons, damage the brain, induce behavioral/psychiatric/cognitive abnormalities and ataxia in animal models, and can be removed or silenced in some patients by immunotherapy. J Neural Transm (Vienna) 2014, 121, 1029-1075, doi:10.1007/s00702-014-1193-3. 
29. Hay, E.M.; Thomas, E.; Pal, B.; Hajeer, A.; Chambers, H.; Silman, A.J. Weak association between subjective symptoms or and objective testing for dry eyes and dry mouth: results from a population based study. Ann Rheum Dis 1998, 57, 20-24.

30. Nichols, K.K.; Nichols, J.J.; Mitchell, G.L. The lack of association between signs and symptoms in patients with dry eye disease. Cornea 2004, 23, 762-770.

31. Vehof, J.; Kozareva, D.; Hysi, P.G.; Harris, J.; Nessa, A.; Williams, F.K.; Bennett, D.L.; McMahon, S.B.; Fahy, S.J.; Direk, K., et al. Relationship between dry eye symptoms and pain sensitivity. JAMA Ophthalmol 2013, 131, 1304-1308, doi:10.1001/jamaophthalmol.2013.4399.

32. Galor, A.; Covington, D.; Levitt, A.E.; McManus, K.T.; Seiden, B.; Felix, E.R.; Kalangara, J.; Feuer, W.; Patin, D.J.; Martin, E.R., et al. Neuropathic Ocular Pain due to Dry Eye Is Associated With Multiple Comorbid Chronic Pain Syndromes. The journal of pain : official journal of the American Pain Society 2016, 17, 310-318, doi:10.1016/j.jpain.2015.10.019.

33. Alves, M.; Reinach, P.S.; Paula, J.S.; Vellasco e Cruz, A.A.; Bachette, L.; Faustino, J.; Aranha, F.P.; Vigorito, A.; de Souza, C.A.; Rocha, E.M. Comparison of diagnostic tests in distinct well-defined conditions related to dry eye disease. PLoS One 2014, 9, e97921, doi:10.1371/journal.pone.0097921.

34. Barboza, M.N.; Barboza, G.N.; de Melo, G.M.; Sato, E.; Dantas, M.C.; Dantas, P.E.; Felberg, S. [Correlation between signals and symptoms 
of dry eye in Sjögren's syndrome patients]. Arq Bras Oftalmol 2008, 71, 547-552, doi:S0004-27492008000400015 [pii].

35. Seror, R.; Gottenberg, J.E.; Devauchelle-Pensec, V.; Dubost, J.J.; Le Guern, V.; Hayem, G.; Fauchais, A.L.; Goeb, V.; Hachulla, E.; Hatron, P.Y., et al. European League Against Rheumatism Sjogren's Syndrome Disease Activity Index and European League Against Rheumatism Sjogren's Syndrome Patient-Reported Index: a complete picture of primary Sjogren's syndrome patients. Arthritis Care Res (Hoboken) 2013, 65, 1358-1364, doi:10.1002/acr.21991.

36. Akesson, K.; Pettersson, S.; Stahl, S.; Surowiec, I.; Hedenstrom, M.; Eketjall, S.; Trygg, J.; Jakobsson, P.J.; Gunnarsson, I.; Svenungsson, E., et al. Kynurenine pathway is altered in patients with SLE and associated with severe fatigue. Lupus Sci Med 2018, 5, e000254, doi:10.1136/lupus-2017-000254.

37. Curzon, G.; Bridges, P.K. Tryptophan metabolism in depression. J Neurol Neurosurg Psychiatry 1970, 33, 698-704.

38. Heyes, M.P.; Saito, K.; Crowley, J.S.; Davis, L.E.; Demitrack, M.A.; Der, M.; Dilling, L.A.; Elia, J.; Kruesi, M.J.; Lackner, A., et al. Quinolinic acid and kynurenine pathway metabolism in inflammatory and noninflammatory neurological disease. Brain 1992, 115 ( Pt 5), 1249-1273.

39. Laumet, G.; Zhou, W.; Dantzer, R.; Edralin, J.D.; Huo, X.; Budac, D.P.; O'Connor, J.C.; Lee, A.W.; Heijnen, C.J.; Kavelaars, A. Upregulation of neuronal kynurenine 3-monooxygenase mediates depression-like behavior in a mouse model of neuropathic pain. Brain Behav Immun 2017, 66, 94-102, doi:10.1016/j.bbi.2017.07.008. 
40. Remus, J.L.; Dantzer, R. Inflammation Models of Depression in Rodents: Relevance to Psychotropic Drug Discovery. Int J Neuropsychopharmacol 2016, 19, doi:10.1093/ijnp/pyw028.

41. Bortolato, B.; Berk, M.; Maes, M.; Mclntyre, R.S.; Carvalho, A.F. Fibromyalgia and Bipolar Disorder: Emerging Epidemiological Associations and Shared Pathophysiology. Curr Mol Med 2016, 16, 119-136.

42. Ter Borg, E.J.; Kelder, J.C. Development of new extra-glandular manifestations or associated auto-immune diseases after establishing the diagnosis of primary Sjogren's syndrome : A long-term study of the Antonius Nieuwegein Sjogren (ANS) cohort. Rheumatology international 2017, 37, 1153-1158, doi:10.1007/s00296-017-3715-4.

43. Valim, V.; Sardemberg, W.M.; Brun, J.G.; Zandonade, E.; Balarini, G.M.; Tanure, L.V.; Ferreira, G.V.; Serrano, 'E.V.; Tonini, J.F.V.; Brokstad, K.A., et al. Interferon-gamma-inducible kynurenines inflammation pathway: the missing link between disease activity and symptoms in Sjögren's syndrome Annals of the Rheumatic Diseases 2017, 76, 1102.

44. Mori, K.; lijima, M.; Koike, H.; Hattori, N.; Tanaka, F.; Watanabe, H.; Katsuno, M.; Fujita, A.; Aiba, I.; Ogata, A., et al. The wide spectrum of clinical manifestations in Sjogren's syndrome-associated neuropathy. Brain 2005, 128, 2518-2534, doi:10.1093/brain/awh605.

45. Alexander, G.E.; Provost, T.T.; Stevens, M.B.; Alexander, E.L. Sjogren syndrome: central nervous system manifestations. Neurology 1981, 31, 1391-1396. 
46. Barendregt, P.J.; van den Bent, M.J.; van Raaij-van den Aarssen, V.J.; van den Meiracker, A.H.; Vecht, C.J.; van der Heijde, G.L.; Markusse, H.M. Involvement of the peripheral nervous system in primary Sjogren's syndrome. Ann Rheum Dis 2001, 60, 876-881.

47. Chai, J.; Logigian, E.L. Neurological manifestations of primary Sjogren's syndrome. Curr Opin Neurol 2010, 23, 509-513, doi:10.1097/WCO.0b013e32833de6ab.

48. Goransson, L.G.; Herigstad, A.; Tjensvoll, A.B.; Harboe, E.; Mellgren, S.I.; Omdal, R. Peripheral neuropathy in primary sjogren syndrome: a population-based study. Arch Neurol 2006, 63, 1612-1615.

49. Indart, S.; Hugon, J.; Guillausseau, P.J.; Gilbert, A.; Dumurgier, J.; Paquet, C.; Sene, D. Impact of pain on cognitive functions in primary Sjogren syndrome with small fiber neuropathy: 10 cases and a literature review. Medicine 2017, 96, e6384, doi:10.1097/MD.0000000000006384.

50. Terkelsen, A.J.; Karlsson, P.; Lauria, G.; Freeman, R.; Finnerup, N.B.; Jensen, T.S. The diagnostic challenge of small fibre neuropathy: clinical presentations, evaluations, and causes. Lancet Neurol 2017, 16, 934-944, doi:10.1016/S1474-4422(17)30329-0.

51. Kocer, B.; Tezcan, M.E.; Batur, H.Z.; Haznedaroglu, S.; Goker, B.; Irkec, C.; Cetinkaya, R. Cognition, depression, fatigue, and quality of life in primary Sjogren's syndrome: correlations. Brain Behav 2016, 6, e00586, doi:10.1002/brb3.586.

52. Tezcan, M.E.; Kocer, E.B.; Haznedaroglu, S.; Sonmez, C.; Mercan, R.; Yucel, A.A.; Irkec, C.; Bitik, B.; Goker, B. Primary Sjogren's syndrome 
is associated with significant cognitive dysfunction. Int $J$ Rheum Dis 2016, 19, 981-988, doi:10.1111/1756-185X.12912.

53. Milin, M.; Cornec, D.; Chastaing, M.; Griner, V.; Berrouiguet, S.; Nowak, E.; Marhadour, T.; Saraux, A.; Devauchelle-Pensec, V. Sicca symptoms are associated with similar fatigue, anxiety, depression, and quality-of-life impairments in patients with and without primary Sjogren's syndrome. Joint Bone Spine 2016, 83, 681-685, doi:10.1016/j.jbspin.2015.10.005.

54. Imrich, R.; Alevizos, I.; Bebris, L.; Goldstein, D.S.; Holmes, C.S.; Illei, G.G.; Nikolov, N.P. Predominant Glandular Cholinergic Dysautonomia in Patients With Primary Sjogren's Syndrome. Arthritis Rheumatol 2015, 67, 1345-1352, doi:10.1002/art.39044.

55. Qiao, L.; Wang, Q.; Fei, Y.; Zhang, W.; Xu, Y.; Zhang, Y.; Zhao, Y.; Zeng, X.; Zhang, F. The Clinical Characteristics of Primary Sjogren's Syndrome With Neuromyelitis Optica Spectrum Disorder in China: A STROBE-Compliant Article. Medicine 2015, 94, e1145, doi:10.1097/MD.0000000000001145.

56. Abu-Amero, K.K.; Helwa, I.; Al-Muammar, A.; Strickland, S.; Hauser, M.A.; Allingham, R.R.; Liu, Y. Screening of the Seed Region of MIR184 in Keratoconus Patients from Saudi Arabia. BioMed research international 2015, 2015, 604508, doi:10.1155/2015/604508.

57. Brito, G.N.; Araujo, G.R.; Papi, J.A. Neuropsychological, neuroimage and psychiatric aspects of primary Sjogren's syndrome. Arquivos de neuro-psiquiatria 2002, 60, 28-31. 
58. Carvalho, D.C.; Tironi, T.S.; Freitas, D.S.; Kleinpaul, R.; Talim, N.C.; Lana-Peixoto, M.A. Sjogren syndrome and neuromyelitis optica spectrum disorder co-exist in a common autoimmune milieu. Arquivos de neuro-psiquiatria 2014, 72, 619-624.

59. Pelizza, L.; Bonacini, F.; Ferrari, A. Psychiatric disorder as clinical presentation of primary Sjogren's syndrome: two case reports. Ann Gen Psychiatry 2010, 9, 12, doi:10.1186/1744-859X-9-12.

60. Wong, J.K.; Nortley, R.; Andrews, T.; D'Cruz, D. Psychiatric manifestations of primary Sjogren's syndrome: a case report and literature review. BMJ Case Rep 2014, 2014, doi:10.1136/bcr-2012008038.

61. Caselli, R.J.; Scheithauer, B.W.; Bowles, C.A.; Trenerry, M.R.; Meyer, F.B.; Smigielski, J.S.; Rodriguez, M. The treatable dementia of Sjogren's syndrome. Ann Neurol 1991, 30, 98-101, doi:10.1002/ana.410300117.

62. Escudero, D.; Latorre, P.; Codina, M.; Coll-Canti, J.; Coll, J. Central nervous system disease in Sjogren's syndrome. Ann Med Interne (Paris) 1995, 146, 239-242.

63. Alexander, E.L.; Provost, T.T.; Stevens, M.B.; Alexander, G.E. Neurologic complications of primary Sjogren's syndrome. Medicine (Baltimore) 1982, 61, 247-257.

64. Lafitte, C.; Amoura, Z.; Cacoub, P.; Pradat-Diehl, P.; Picq, C.; Salachas, F.; Leger, J.M.; Piette, J.C.; Delattre, J.Y. Neurological complications of primary Sjogren's syndrome. J Neurol 2001, 248, 577584. 
65. Gemignani, F.; Marbini, A.; Pavesi, G.; Di Vittorio, S.; Manganelli, P.; Cenacchi, G.; Mancia, D. Peripheral neuropathy associated with primary Sjogren's syndrome. J Neurol Neurosurg Psychiatry 1994, 57, 983-986.

66. Govoni, M.; Bajocchi, G.; Rizzo, N.; Tola, M.R.; Caniatti, L.; Tugnoli, V.; Colamussi, P.; Trotta, F. Neurological involvement in primary Sjogren's syndrome: clinical and instrumental evaluation in a cohort of Italian patients. Clin Rheumatol 1999, 18, 299-303.

67. Lopate, G.; Pestronk, A.; Al-Lozi, M.; Lynch, T.; Florence, J.; Miller, T.; Levine, T.; Rampy, T.; Beson, B.; Ramneantu, I. Peripheral neuropathy in an outpatient cohort of patients with Sjogren's syndrome. Muscle Nerve 2006, 33, 672-676, doi:10.1002/mus.20514.

68. Kawashima, N.; Shindo, R.; Kohno, M. Primary Sjogren's syndrome with subcortical dementia. Intern Med 1993, 32, 561-564.

69. Teixeira, F.; Moreira, I.; Silva, A.M.; Vasconcelos, C.; Farinha, F.; Santos, E. Neurological involvement in Primary Sjogren Syndrome. Acta Reumatol Port 2013, 38, 29-36.

70. Michel, L.; Toulgoat, F.; Desal, H.; Laplaud, D.A.; Magot, A.; Hamidou, M.; Wiertlewski, S. Atypical neurologic complications in patients with primary Sjogren's syndrome: report of 4 cases. Semin Arthritis Rheum 2011, 40, 338-342, doi:10.1016/j.semarthrit.2010.06.005.

71. Nitescu, D.; Nicolau, A.; Caraiola, S.; Predeteanu, D.; lonescu, R.; Tanasescu, C. Neuromyelitis optica--complication or comorbidity in primary Sjogren's syndrome? Rom J Intern Med 2011, 49, 295-300. 
72. Brito-Zeron, P.; Akasbi, M.; Bosch, X.; Bove, A.; Perez-De-Lis, M.; Diaz-Lagares, C.; Retamozo, S.; Gandia, M.; Perez-Alvarez, R.; SotoCardenas, M.J., et al. Classification and characterisation of peripheral neuropathies in 102 patients with primary Sjogren's syndrome. Clin Exp Rheumatol 2013, 31, 103-110.

73. Liu, J.Y.; Zhao, T.; Zhou, C.K. Central nervous system involvement in primary Sjogren`s syndrome manifesting as multiple sclerosis. Neurosciences (Riyadh) 2014, 19, 134-137.

74. Pavlakis, P.P.; Alexopoulos, H.; Kosmidis, M.L.; Stamboulis, E.; Routsias, J.G.; Tzartos, S.J.; Tzioufas, A.G.; Moutsopoulos, H.M.; Dalakas, M.C. Peripheral neuropathies in Sjogren syndrome: a new reappraisal. J Neurol Neurosurg Psychiatry 2011, 82, 798-802, doi:10.1136/jnnp.2010.222109.

75. Hasiloglu, Z.I.; Albayram, S.; Tasmali, K.; Erer, B.; Selcuk, H.; Islak, C. A case of primary Sjogren's syndrome presenting primarily with central nervous system vasculitic involvement. Rheumatol Int 2012, 32, 805807, doi:10.1007/s00296-011-1824-z.

76. Koh, J.H.; Kwok, S.K.; Lee, J.; Park, S.H. Autonomic dysfunction in primary Sjogren's syndrome: a prospective cohort analysis of 154 Korean patients. Korean J Intern Med 2017, 32, 165-173, doi:10.3904/kjim.2015.219.

77. Yoshida, T.; Sueyoshi, T.; Suwazono, S.; Kinjo, M.; Nodera, H. Detection of atrophy of dorsal root ganglion with 3-T magnetic resonance neurography in sensory ataxic neuropathy associated with 
Sjogren's syndrome. Eur J Neurol 2018, 25, e78-e79, doi:10.1111/ene.13647.

78. Lauvsnes, M.B.; Beyer, M.K.; Appenzeller, S.; Greve, O.J.; Harboe, E.; Goransson, L.G.; Tjensvoll, A.B.; Omdal, R. Loss of cerebral white matter in primary Sjogren's syndrome: a controlled volumetric magnetic resonance imaging study. Eur J Neurol 2014, 21, 1324-1329, doi:10.1111/ene.12486.

79. Mori, K.; Koike, H.; Misu, K.; Hattori, N.; Ichimura, M.; Sobue, G. Spinal cord magnetic resonance imaging demonstrates sensory neuronal involvement and clinical severity in neuronopathy associated with Sjogren's syndrome. J Neurol Neurosurg Psychiatry 2001, 71, 488-492.

80. Sullivan, D.A.; Wickham, L.A.; Rocha, E.M.; Krenzer, K.L.; Sullivan, B.D.; Steagall, R.; Cermak, J.M.; Dana, M.R.; Ullman, M.D.; Sato, E.H., et al. Androgens and dry eye in Sjogren's syndrome. Annals of the New York Academy of Sciences 1999, 876, 312-324.

81. Pavlakis, P.P.; Alexopoulos, H.; Kosmidis, M.L.; Mamali, I.; Moutsopoulos, H.M.; Tzioufas, A.G.; Dalakas, M.C. Peripheral neuropathies in Sjogren's syndrome: a critical update on clinical features and pathogenetic mechanisms. Journal of autoimmunity 2012, 39, 27-33, doi:10.1016/j.jaut.2012.01.003.

82. Roberts, A.L.; Malspeis, S.; Kubzansky, L.D.; Feldman, C.H.; Chang, S.C.; Koenen, K.C.; Costenbader, K.H. Association of Trauma and Posttraumatic Stress Disorder With Incident Systemic Lupus Erythematosus in a Longitudinal Cohort of Women. Arthritis Rheumatol 2017, 69, 2162-2169, doi:10.1002/art.40222. 
83. Konsta, O.D.; Thabet, Y.; Le Dantec, C.; Brooks, W.H.; Tzioufas, A.G.; Pers, J.O.; Renaudineau, Y. The contribution of epigenetics in Sjogren's Syndrome. Frontiers in genetics 2014, 5, 71, doi:10.3389/fgene.2014.00071.

84. Garcia-Carrasco, M.; Fuentes-Alexandro, S.; Escarcega, R.O.; Salgado, G.; Riebeling, C.; Cervera, R. Pathophysiology of Sjogren's syndrome. Arch Med Res 2006, 37, 921-932.

85. Li, H.; Reksten, T.R.; Ice, J.A.; Kelly, J.A.; Adrianto, I.; Rasmussen, A.; Wang, S.; He, B.; Grundahl, K.M.; Glenn, S.B., et al. Identification of a Sjogren's syndrome susceptibility locus at OAS1 that influences isoform switching, protein expression, and responsiveness to type I interferons. PLoS Genet 2017, 13, e1006820, doi:10.1371/journal.pgen.1006820.

86. Owada, K.; Uchihara, T.; Ishida, K.; Mizusawa, H.; Watabiki, S.; Tsuchiya, K. Motor weakness and cerebellar ataxia in Sjogren syndrome--identification of antineuronal antibody: a case report. Journal of the neurological sciences 2002, 197, 79-84.

87. Rosler, D.H.; Conway, M.D.; Anaya, J.M.; Molina, J.F.; Carr, R.F.; Gharavi, A.E.; Wilson, W.A. Ischemic optic neuropathy and high-level anticardiolipin antibodies in primary Sjogren's syndrome. Lupus 1995, 4, 155-157.

88. Rassi, D.M.; De Paiva, C.S.; Dias, L.C.; Modulo, C.M.; Adriano, L.; Fantucci, M.Z.; Rocha, E.M. MicroRNAs in ocular surface and dry eye diseases: Good, bad and healing situations. Ocul Surf 2017, 10.1016/j.jtos.2017.05.007, doi:10.1016/j.jtos.2017.05.007. 
89. Josephs, K.A.; Rubino, F.A.; Dickson, D.W. Nonvasculitic autoimmune inflammatory meningoencephalitis. Neuropathology 2004, 24, 149-152.

90. Imada, T.; Nakamura, S.; Hisamura, R.; Izuta, Y.; Jin, K.; Ito, M.; Kitamura, N.; Tanaka, K.F.; Mimura, M.; Shibuya, I., et al. Serotonin hormonally regulates lacrimal gland secretory function via the serotonin type 3a receptor. Scientific reports 2017, 7, 6965, doi:10.1038/s41598017-06022-4.

91. Rojewska, E.; Piotrowska, A.; Makuch, W.; Przewlocka, B.; Mika, J. Pharmacological kynurenine 3-monooxygenase enzyme inhibition significantly reduces neuropathic pain in a rat model.

Neuropharmacology 2016, 102, 80-91, doi:10.1016/j.neuropharm.2015.10.040.

92. Akpek, E.K.; Mathews, P.; Hahn, S.; Hessen, M.; Kim, J.; Grader-Beck, T.; Birnbaum, J.; Baer, A.N. Ocular and systemic morbidity in a longitudinal cohort of Sjögren's syndrome. Ophthalmology 2015, 122, 56-61, doi:10.1016/j.ophtha.2014.07.026.

93. Belmonte, C.; Nichols, J.J.; Cox, S.M.; Brock, J.A.; Begley, C.G.; Bereiter, D.A.; Dartt, D.A.; Galor, A.; Hamrah, P.; Ivanusic, J.J., et al. TFOS DEWS II pain and sensation report. Ocul Surf 2017, 15, 404-437, doi:10.1016/j.jtos.2017.05.002.

94. Kawai, Y.; Sumi, M.; Kitamori, H.; Takagi, Y.; Nakamura, T. Diffusionweighted MR microimaging of the lacrimal glands in patients with Sjogren's syndrome. AJR Am J Roentgenol 2005, 184, 1320-1325, doi:10.2214/ajr.184.4.01841320. 
95. Demeter, I.; Nagy, K.; Farkas, T.; Kis, Z.; Kocsis, K.; Knapp, L.; Gellert, L.; Fulop, F.; Vecsei, L.; Toldi, J. Paradox effects of kynurenines on LTP induction in the Wistar rat. An in vivo study. Neuroscience letters 2013, 553, 138-141, doi:10.1016/j.neulet.2013.08.028.

96. Birnbaum, J.; Duncan, T.; Owoyemi, K.; Wang, K.C.; Carrino, J.; Chhabra, A. Use of a novel high-resolution magnetic resonance neurography protocol to detect abnormal dorsal root Ganglia in Sjogren patients with neuropathic pain: case series of 10 patients and review of the literature. Medicine 2014, 93, 121-134,

doi:10.1097/MD.0000000000000024.

97. Saito, K.; Quearry, B.J.; Saito, M.; Nowak, T.S., Jr.; Markey, S.P.; Heyes, M.P. Kynurenine 3-hydroxylase in brain: species activity differences and effect of gerbil cerebral ischemia. Arch Biochem Biophys 1993, 307, 104-109, doi:10.1006/abbi.1993.1567.

98. Kojima, I.; Sakamoto, M.; likubo, M.; Shimada, Y.; Nishioka, T.; Sasano, T. Relationship of MR imaging of submandibular glands to hyposalivation in Sjogren's syndrome. Oral Dis 2018, 10.1111/odi.12941, doi:10.1111/odi.12941.

99. Ikeno, K.; Saikatsu, S.; Uno, T.; Ikeno, T. Effects of prolonged duct ligation of the rat salivary glands on the activity of trypsin-like protease. Archives of oral biology 1988, 33, 613-615.

100. Kelleher, R.S.; Hann, L.E.; Edwards, J.A.; Sullivan, D.A. Endocrine, neural, and immune control of secretory component output by lacrimal gland acinar cells. J Immunol 1991, 146, 3405-3412. 
101. Bacman, S.; Berra, A.; Sterin-Borda, L.; Borda, E. Muscarinic acetylcholine receptor antibodies as a new marker of dry eye Sjögren syndrome. Invest Ophthalmol Vis Sci 2001, 42, 321-327.

102. Tzioufas, A.G.; Tsonis, J.; Moutsopoulos, H.M. Neuroendocrine dysfunction in Sjogren's syndrome. Neuroimmunomodulation 2008, 15, 37-45.

103. Wilder, R.L. Neuroendocrine-immune system interactions and autoimmunity. Annu Rev Immunol 1995, 13, 307-338.

104. Rosas-Ballina, M.; Olofsson, P.S.; Ochani, M.; Valdes-Ferrer, S.I.; Levine, Y.A.; Reardon, C.; Tusche, M.W.; Pavlov, V.A.; Andersson, U.; Chavan, S., et al. Acetylcholine-synthesizing T cells relay neural signals in a vagus nerve circuit. Science 2011, 334, 98-101, doi:10.1126/science.1209985.

105. Ueno, M.; Ueno-Nakamura, Y.; Niehaus, J.; Popovich, P.G.; Yoshida, Y. Silencing spinal interneurons inhibits immune suppressive autonomic reflexes caused by spinal cord injury. Nature neuroscience 2016, 19, 784-787, doi:10.1038/nn.4289.

106. Mina-Osorio, P.; Rosas-Ballina, M.; Valdes-Ferrer, S.I.; Al-Abed, Y.; Tracey, K.J.; Diamond, B. Neural signaling in the spleen controls B-cell responses to blood-borne antigen. Mol Med 2012, 18, 618-627, doi:10.2119/molmed.2012.00027.

107. Mirakaj, V.; Dalli, J.; Granja, T.; Rosenberger, P.; Serhan, C.N. Vagus nerve controls resolution and pro-resolving mediators of inflammation. J Exp Med 2014, 211, 1037-1048, doi:10.1084/jem.20132103. 
108. Chiu, I.M.; Heesters, B.A.; Ghasemlou, N.; Von Hehn, C.A.; Zhao, F.; Tran, J.; Wainger, B.; Strominger, A.; Muralidharan, S.; Horswill, A.R., et al. Bacteria activate sensory neurons that modulate pain and inflammation. Nature 2013, 501, 52-57, doi:10.1038/nature12479.

109. Kumar, V.; Sur, V.P.; Guha, R.; Konar, A.; Hazra, S. Estrogen Modulates Corneal Nociception and Maintains Corneal Homeostasis in Rat Eye. Cornea 2017, 10.1097/ICO.0000000000001437, doi:10.1097/ICO.0000000000001437.

110. Rocha, E.; Wickham, L.; Huang, Z.; Toda, I.; Gao, J.; da Silveira, L.; Sullivan, D.; Dartt, D.; Meneray, M. Presence and testosterone influence on the levels of anti- and pro-inflammatory cytokines in lacrimal tissues of a mouse model of Sjogren's syndrome; 1998; Vol. 438, pp. 485-491.

111. Sullivan, D.A.; Rocha, E.M.; Aragona, P.; Clayton, J.A.; Ding, J.; Golebiowski, B.; Hampel, U.; McDermott, A.M.; Schaumberg, D.A.; Srinivasan, S., et al. TFOS DEWS II Sex, Gender, and Hormones Report. Ocul Surf 2017, 15, 284-333, doi:10.1016/j.jtos.2017.04.001.

112. Payrits, M.; Saghy, E.; Cseko, K.; Pohoczky, K.; Bolcskei, K.; Ernszt, D.; Barabas, K.; Szolcsanyi, J.; Abraham, I.M.; Helyes, Z., et al. Estradiol Sensitizes the Transient Receptor Potential Vanilloid 1 Receptor in Pain Responses. Endocrinology 2017, 158, 3249-3258, doi:10.1210/en.2017-00101.

113. Flake, N.M.; Bonebreak, D.B.; Gold, M.S. Estrogen and inflammation increase the excitability of rat temporomandibular joint afferent neurons. 
Journal of neurophysiology 2005, 93, 1585-1597, doi:10.1152/jn.00269.2004.

114. Wu, Y.W.; Kou, X.X.; Bi, R.Y.; Xu, W.; Wang, K.W.; Gan, Y.H.; Ma, X.C. Hippocampal nerve growth factor potentiated by 17 beta-estradiol and involved in allodynia of inflamed TMJ in rat. The journal of pain : official journal of the American Pain Society 2012, 13, 555-563, doi:10.1016/j.jpain.2012.03.005.

115. Bi, R.Y.; Meng, Z.; Zhang, P.; Wang, X.D.; Ding, Y.; Gan, Y.H. Estradiol upregulates voltage-gated sodium channel 1.7 in trigeminal ganglion contributing to hyperalgesia of inflamed TMJ. PLOS One 2017, 12, e0178589, doi:10.1371/journal.pone.0178589.

116. Jin, X.; Wang, B.H.; Wang, X.; Antony, B.; Zhu, Z.; Han, W.; Cicuttini, F.; Wluka, A.E.; Winzenberg, T.; Blizzard, L., et al. Associations between endogenous sex hormones and MRI structural changes in patients with symptomatic knee osteoarthritis. Osteoarthritis Cartilage 2017, 25, 1100-1106, doi:10.1016/j.joca.2017.01.015.

117. Sullivan, D.A.; Belanger, A.; Cermak, J.M.; Berube, R.; Papas, A.S.; Sullivan, R.M.; Yamagami, H.; Dana, M.R.; Labrie, F. Are women with Sjogren's syndrome androgen-deficient? J Rheumatol 2003, 30, 24132419.

118. Sullivan, D.A. Sex hormones and Sjogren's syndrome. J Rheumatol Suppl 1997, 50, 17-32.

119. Taiym, S.; Haghighat, N.; Al-Hashimi, I. A comparison of the hormone levels in patients with Sjogren's syndrome and healthy controls. Oral 
Surg Oral Med Oral Pathol Oral Radiol Endod 2004, 97, 579-583, doi:10.1016/S107921040400068X.

120. Woller, S.A.; Eddinger, K.A.; Corr, M.; Yaksh, T.L. An overview of pathways encoding nociception. Clin Exp Rheumatol 2017, 35 Suppl $107,40-46$.

121. Rosenthal, P.; Borsook, D. Ocular neuropathic pain. Br J Ophthalmol 2016, 100, 128-134, doi:10.1136/bjophthalmol-2014-306280.

122. Sandhya, P.; Jeyaseelan, L.; Scofield, R.H.; Danda, D. Clinical Characteristics and Outcome of Primary Sjogren's Syndrome: A Large Asian Indian Cohort. Open Rheumatol J 2015, 9, 36-45, doi:10.2174/1874312901409010036.

123. Ruddick, J.P.; Evans, A.K.; Nutt, D.J.; Lightman, S.L.; Rook, G.A.; Lowry, C.A. Tryptophan metabolism in the central nervous system: medical implications. Expert Rev Mol Med 2006, 8, 1-27, doi:10.1017/S1462399406000068.

124. Nakamura, T.; Shinno, H.; Ichihara, A. Insulin and glucagon as a new regulator system for tryptophan oxygenase activity demonstrated in primary cultured rat hepatocytes. J Biol Chem 1980, 255, 7533-7535.

125. Heyes, M.P.; Saito, K.; Milstien, S.; Schiff, S.J. Quinolinic acid in tumors, hemorrhage and bacterial infections of the central nervous system in children. Journal of the neurological sciences 1995, 133, 112-118.

126. Hayaishi, O. Properties and function of indoleamine 2,3-dioxygenase. $J$ Biochem 1976, 79, 13P-21P. 
127. Hayaishi, O.; Yoshida, R. Specific induction of pulmonary indoleamine 2,3-dioxygenase by bacterial lipopolysaccharide. Ciba Found Symp 1978, 199-203.

128. Wolf, $\mathrm{H}$. The effect of hormones and vitamin B6 on urinary excretion of metabolites of the kynurenine pathway. Scand J Clin Lab Invest SuppI 1974, 136, 1-186.

129. Munn, D.H.; Shafizadeh, E.; Attwood, J.T.; Bondarev, I.; Pashine, A.; Mellor, A.L. Inhibition of T cell proliferation by macrophage tryptophan catabolism. J Exp Med 1999, 189, 1363-1372.

130. Munn, D.H.; Zhou, M.; Attwood, J.T.; Bondarev, I.; Conway, S.J.; Marshall, B.; Brown, C.; Mellor, A.L. Prevention of allogeneic fetal rejection by tryptophan catabolism. Science 1998, 281, 1191-1193.

131. Puccetti, P.; Grohmann, U. IDO and regulatory T cells: a role for reverse signalling and non-canonical NF-kappaB activation. Nat Rev Immunol 2007, 7, 817-823, doi:10.1038/nri2163.

132. Maria, N.I.; van Helden-Meeuwsen, C.G.; Brkic, Z.; Paulissen, S.M.; Steenwijk, E.C.; Dalm, V.A.; van Daele, P.L.; Martin van Hagen, P.; Kroese, F.G.; van Roon, J.A., et al. Association of Increased Treg Cell Levels With Elevated Indoleamine 2,3-Dioxygenase Activity and an Imbalanced Kynurenine Pathway in Interferon-Positive Primary Sjogren's Syndrome. Arthritis Rheumatol 2016, 68, 1688-1699, doi:10.1002/art.39629.

133. Mellor, A.L.; Munn, D.H. IDO expression by dendritic cells: tolerance and tryptophan catabolism. Nat Rev Immunol 2004, 4, 762-774, doi: $10.1038 / n r i 1457$. 
134. Munn, D.H.; Armstrong, E. Cytokine regulation of human monocyte differentiation in vitro: the tumor-cytotoxic phenotype induced by macrophage colony-stimulating factor is developmentally regulated by gamma-interferon. Cancer Res 1993, 53, 2603-2613.

135. Heyes, M.P.; Saito, K.; Jacobowitz, D.; Markey, S.P.; Takikawa, O.; Vickers, J.H. Poliovirus induces indoleamine-2,3-dioxygenase and quinolinic acid synthesis in macaque brain. FASEB $J$ 1992, 6, 29772989.

136. Saito, K.; Lackner, A.; Markey, S.P.; Heyes, M.P. Cerebral cortex and lung indoleamine-2,3-dioxygenase activity is increased in type-D retrovirus infected macaques. Brain Res 1991, 540, 353-356.

137. Saito, K.; Markey, S.P.; Heyes, M.P. Chronic effects of gammainterferon on quinolinic acid and indoleamine-2,3-dioxygenase in brain of C57BL6 mice. Brain Res 1991, 546, 151-154.

138. Sayama, S.; Yoshida, R.; Oku, T.; Imanishi, J.; Kishida, T.; Hayaishi, O. Inhibition of interferon-mediated induction of indoleamine 2,3dioxygenase in mouse lung by inhibitors of prostaglandin biosynthesis. Proc Natl Acad Sci U S A 1981, 78, 7327-7330.

139. Yoshida, R.; Urade, Y.; Nakata, K.; Watanabe, Y.; Hayaishi, O. Specific induction of indoleamine 2,3-dioxygenase by bacterial lipopolysaccharide in the mouse lung. Arch Biochem Biophys 1981, 212, 629-637.

140. Pertovaara, M.; Raitala, A.; Uusitalo, H.; Pukander, J.; Helin, H.; Oja, S.S.; Hurme, M. Mechanisms dependent on tryptophan catabolism 
regulate immune responses in primary Sjogren's syndrome. Clin Exp Immunol 2005, 142, 155-161, doi:10.1111/j.1365-2249.2005.02889.x.

141. Campbell, D.J.; Koch, M.A. Treg cells: patrolling a dangerous neighborhood. Nat Med 2011, 17, 929-930, doi:10.1038/nm.2433.

142. Jasperson, L.K.; Bucher, C.; Panoskaltsis-Mortari, A.; Mellor, A.L.; Munn, D.H.; Blazar, B.R. Inducing the tryptophan catabolic pathway, indoleamine 2,3-dioxygenase (IDO), for suppression of graft-versushost disease (GVHD) lethality. Blood 2009, 114, 5062-5070, doi:10.1182/blood-2009-06-227587.

143. Nezos, A.; Gravani, F.; Tassidou, A.; Kapsogeorgou, E.K.; Voulgarelis, M.; Koutsilieris, M.; Crow, M.K.; Mavragani, C.P. Type I and II interferon signatures in Sjogren's syndrome pathogenesis:

Contributions in distinct clinical phenotypes and Sjogren's related lymphomagenesis. Journal of autoimmunity $2015,63,47-58$, doi:10.1016/j.jaut.2015.07.002.

144. Raitala, A.; Pertovaara, M.; Karjalainen, J.; Oja, S.S.; Hurme, M. Association of interferon-gamma $+874(\mathrm{~T} / \mathrm{A})$ single nucleotide polymorphism with the rate of tryptophan catabolism in healthy individuals. Scand J Immunol 2005, 61, 387-390, doi:10.1111/j.13653083.2005.01586.x.

145. Silver, R.M.; McKinley, K.; Smith, E.A.; Quearry, B.; Harati, Y.; Sternberg, E.M.; Heyes, M.P. Tryptophan metabolism via the kynurenine pathway in patients with the eosinophilia-myalgia syndrome. Arthritis and rheumatism 1992, 35, 1097-1105. 
146. Barbosa, F.L.; Xiao, Y.; Bian, F.; Coursey, T.G.; Ko, B.Y.; Clevers, H.; de Paiva, C.S.; Pflugfelder, S.C. Goblet Cells Contribute to Ocular Surface Immune Tolerance-Implications for Dry Eye Disease. International journal of molecular sciences 2017, 18, doi:10.3390/ijms18050978.

147. Baboonian, C.; Venables, P.J.; Booth, J.; Williams, D.G.; Roffe, L.M.; Maini, R.N. Virus infection induces redistribution and membrane localization of the nuclear antigen La (SS-B): a possible mechanism for autoimmunity. Clin Exp Immunol 1989, 78, 454-459.

148. Thorlacius, G.E.; Wahren-Herlenius, M.; Ronnblom, L. An update on the role of type I interferons in systemic lupus erythematosus and Sjogren's syndrome. Curr Opin Rheumatol 2018, 30, 471-481, doi:10.1097/BOR.0000000000000524.

149. Prendergast, G.C.; Metz, R.; Muller, A.J.; Merlo, L.M.; Mandik-Nayak, L. IDO2 in Immunomodulation and Autoimmune Disease. Front Immunol 2014, 5, 585, doi:10.3389/fimmu.2014.00585.

150. Murakami, Y.; Saito, K. Species and cell types difference in tryptophan metabolism. Int J Tryptophan Res 2013, 6, 47-54, doi:10.4137/IJTR.S11558.

151. Maes, M.; De Ruyter, M.; Hobin, P.; Suy, E. Relationship between the dexamethasone suppression test and the L-tryptophan/competing amino acids ratio in depression. Psychiatry Res 1987, 21, 323-335.

152. Maes, M.; Meltzer, H.Y.; Scharpe, S.; Bosmans, E.; Suy, E.; De Meester, I.; Calabrese, J.; Cosyns, P. Relationships between lower 
plasma L-tryptophan levels and immune-inflammatory variables in depression. Psychiatry Res 1993, 49, 151-165.

153. Schwarcz, R.; Pellicciari, R. Manipulation of brain kynurenines: glial targets, neuronal effects, and clinical opportunities. J Pharmacol Exp Ther 2002, 303, 1-10, doi:10.1124/jpet.102.034439.

154. Bonaccorso, S.; Marino, V.; Puzella, A.; Pasquini, M.; Biondi, M.; Artini, M.; Almerighi, C.; Verkerk, R.; Meltzer, H.; Maes, M. Increased depressive ratings in patients with hepatitis $\mathrm{C}$ receiving interferonalpha-based immunotherapy are related to interferon-alpha-induced changes in the serotonergic system. Journal of clinical psychopharmacology 2002, 22, 86-90.

155. Capuron, L.; Ravaud, A.; Neveu, P.J.; Miller, A.H.; Maes, M.; Dantzer, R. Association between decreased serum tryptophan concentrations and depressive symptoms in cancer patients undergoing cytokine therapy. Mol Psychiatry 2002, 7, 468-473, doi:10.1038/sj.mp.4000995.

156. Myint, A.M.; Bondy, B.; Baghai, T.C.; Eser, D.; Nothdurfter, C.; Schule, C.; Zill, P.; Muller, N.; Rupprecht, R.; Schwarz, M.J. Tryptophan metabolism and immunogenetics in major depression: a role for interferon-gamma gene. Brain Behav Immun 2013, 31, 128-133, doi:10.1016/j.bbi.2013.04.003.

157. Myint, A.M.; Kim, Y.K. Network beyond IDO in psychiatric disorders: revisiting neurodegeneration hypothesis. Prog Neuropsychopharmacol Biol Psychiatry 2014, 48, 304-313, doi:10.1016/j.pnpbp.2013.08.008.

158. O'Farrell, K.; Harkin, A. Stress-related regulation of the kynurenine pathway: Relevance to neuropsychiatric and degenerative disorders. 
Neuropharmacology 2017, 112, 307-323,

doi:10.1016/j.neuropharm.2015.12.004.

159. Kennedy, P.J.; Cryan, J.F.; Dinan, T.G.; Clarke, G. Kynurenine pathway metabolism and the microbiota-gut-brain axis.

Neuropharmacology 2017, 112, 399-412,

doi:10.1016/j.neuropharm.2016.07.002.

160. DeLuca, J.A.; Allred, K.F.; Menon, R.; Riordan, R.; Weeks, B.R.; Jayaraman, A.; Allred, C.D. Bisphenol-A alters microbiota metabolites derived from aromatic amino acids and worsens disease activity during colitis. Exp Biol Med (Maywood) 2018, 243, 864-875, doi:10.1177/1535370218782139.

161. Hertzman, P.A.; Blevins, W.L.; Mayer, J.; Greenfield, B.; Ting, M.; Gleich, G.J. Association of the eosinophilia-myalgia syndrome with the ingestion of tryptophan. N Engl J Med 1990, 322, 869-873, doi:10.1056/NEJM199003293221301.

162. Young, S.N.; Smith, S.E.; Pihl, R.O.; Ervin, F.R. Tryptophan depletion causes a rapid lowering of mood in normal males.

Psychopharmacology (Berl) 1985, 87, 173-177.

163. Guillemin, G.J.; Kerr, S.J.; Smythe, G.A.; Smith, D.G.; Kapoor, V.; Armati, P.J.; Croitoru, J.; Brew, B.J. Kynurenine pathway metabolism in human astrocytes: a paradox for neuronal protection. J Neurochem $2001,78,842-853$.

164. Guillemin, G.J.; Williams, K.R.; Smith, D.G.; Smythe, G.A.; CroitoruLamoury, J.; Brew, B.J. Quinolinic acid in the pathogenesis of Alzheimer's disease. Adv Exp Med Biol 2003, 527, 167-176. 
165. Guillemin, G.J. Quinolinic acid, the inescapable neurotoxin. FEBS J 2012, 279, 1356-1365, doi:10.1111/j.1742-4658.2012.08485.x.

166. O'Farrell, K.; Fagan, E.; Connor, T.J.; Harkin, A. Inhibition of the kynurenine pathway protects against reactive microglial-associated reductions in the complexity of primary cortical neurons. Eur $J$ Pharmacol 2017, 810, 163-173, doi:10.1016/j.ejphar.2017.07.008.

167. Colin-Gonzalez, A.L.; Maldonado, P.D.; Santamaria, A. 3Hydroxykynurenine: an intriguing molecule exerting dual actions in the central nervous system. Neurotoxicology 2013, 34, 189-204, doi:10.1016/j.neuro.2012.11.007.

168. Eastman, C.L.; Guilarte, T.R. Cytotoxicity of 3-hydroxykynurenine in a neuronal hybrid cell line. Brain Res 1989, 495, 225-231.

169. Eastman, C.L.; Guilarte, T.R.; Lever, J.R. Uptake of 3hydroxykynurenine measured in rat brain slices and in a neuronal cell line. Brain Res 1992, 584, 110-116.

170. Schwarcz, R.; Stone, T.W. The kynurenine pathway and the brain: Challenges, controversies and promises. Neuropharmacology 2017, 112, 237-247, doi:10.1016/j.neuropharm.2016.08.003.

171. Shigemoto, R.; Nakanishi, S.; Mizuno, N. Distribution of the mRNA for a metabotropic glutamate receptor (mGluR1) in the central nervous system: an in situ hybridization study in adult and developing rat. $J$ Comp Neurol 1992, 322, 121-135, doi:10.1002/cne.903220110.

172. Arnone, D.; Job, D.; Selvaraj, S.; Abe, O.; Amico, F.; Cheng, Y.; Colloby, S.J.; O'Brien, J.T.; Frodl, T.; Gotlib, I.H., et al. Computational 
meta-analysis of statistical parametric maps in major depression. Hum Brain Mapp 2016, 37, 1393-1404, doi:10.1002/hbm.23108.

173. Castle, M.; Comoli, E.; Loewy, A.D. Autonomic brainstem nuclei are linked to the hippocampus. Neuroscience 2005, 134, 657-669, doi:10.1016/j.neuroscience.2005.04.031.

174. Petralia, R.S.; Wang, Y.X.; Wenthold, R.J. The NMDA receptor subunits NR2A and NR2B show histological and ultrastructural localization patterns similar to those of NR1. The Journal of neuroscience : the official journal of the Society for Neuroscience 1994, $14,6102-6120$

175. Petrenko, A.B.; Yamakura, T.; Baba, H.; Sakimura, K. Unaltered painrelated behavior in mice lacking NMDA receptor GluRepsilon 1 subunit. Neurosci Res 2003, 46, 199-204.

176. Kim, H.; Chen, L.; Lim, G.; Sung, B.; Wang, S.; McCabe, M.F.; Rusanescu, G.; Yang, L.; Tian, Y.; Mao, J. Brain indoleamine 2,3dioxygenase contributes to the comorbidity of pain and depression. $J$ Clin Invest 2012, 122, 2940-2954, doi:10.1172/JCI61884.

177. Petrenko, A.B.; Yamakura, T.; Baba, H.; Shimoji, K. The role of Nmethyl-D-aspartate (NMDA) receptors in pain: a review. Anesth Analg 2003, 97, 1108-1116.

178. Karageorgas, T.; Fragioudaki, S.; Nezos, A.; Karaiskos, D.; Moutsopoulos, H.M.; Mavragani, C.P. Fatigue in Primary Sjogren's Syndrome: Clinical, Laboratory, Psychometric, and Biologic Associations. Arthritis Care Res (Hoboken) 2016, 68, 123-131, doi:10.1002/acr.22720. 
179. Bengtsson, A.A.; Trygg, J.; Wuttge, D.M.; Sturfelt, G.; Theander, E.; Donten, M.; Moritz, T.; Sennbro, C.J.; Torell, F.; Lood, C., et al. Metabolic Profiling of Systemic Lupus Erythematosus and Comparison with Primary Sjogren's Syndrome and Systemic Sclerosis. PLoS One 2016, 11, e0159384, doi:10.1371/journal.pone.0159384.

180. McEwen, B.S. Plasticity of the hippocampus: adaptation to chronic stress and allostatic load. Annals of the New York Academy of Sciences 2001, 933, 265-277.

181. Brake, W.G.; Alves, S.E.; Dunlop, J.C.; Lee, S.J.; Bulloch, K.; Allen, P.B.; Greengard, P.; McEwen, B.S. Novel target sites for estrogen action in the dorsal hippocampus: an examination of synaptic proteins. Endocrinology 2001, 142, 1284-1289, doi:10.1210/endo.142.3.8036.

182. McEwen, B.S. Sex, stress and the hippocampus: allostasis, allostatic load and the aging process. Neurobiol Aging 2002, 23, 921-939.

183. Woolley, C.S.; Weiland, N.G.; McEwen, B.S.; Schwartzkroin, P.A. Estradiol increases the sensitivity of hippocampal CA1 pyramidal cells to NMDA receptor-mediated synaptic input: correlation with dendritic spine density. The Journal of neuroscience : the official journal of the Society for Neuroscience 1997, 17, 1848-1859.

184. Arnone, D.; Saraykar, S.; Salem, H.; Teixeira, A.L.; Dantzer, R.; Selvaraj, S. Role of Kynurenine pathway and its metabolites in mood disorders: A systematic review and meta-analysis of clinical studies. Neurosci Biobehav Rev 2018, 92, 477-485, doi:10.1016/j.neubiorev.2018.05.031. 
185. Dostal, C.R.; Gamsby, N.S.; Lawson, M.A.; McCusker, R.H. Glia- and tissue-specific changes in the Kynurenine Pathway after treatment of mice with lipopolysaccharide and dexamethasone. Brain Behav Immun 2018, 69, 321-335, doi:10.1016/j.bbi.2017.12.006.

186. Zhuo, M. Ionotropic glutamate receptors contribute to pain transmission and chronic pain. Neuropharmacology 2017, 112, 228-234, doi:10.1016/j.neuropharm.2016.08.014.

187. Zhuo, M. Silent glutamatergic synapses and long-term facilitation in spinal dorsal horn neurons. Prog Brain Res 2000, 129, 101-113, doi:10.1016/S0079-6123(00)29008-0.

188. Ciranna, L. Serotonin as a modulator of glutamate- and GABAmediated neurotransmission: implications in physiological functions and in pathology. Curr Neuropharmacol 2006, 4, 101-114.

189. Gandolfi, O.; Gaggi, R.; Voltattorni, M.; Dall'Olio, R. The activation of serotonin receptors prevents glutamate-induced neurotoxicity and NMDA-stimulated cGMP accumulation in primary cortical cell cultures. Pharmacol Res 2002, 46, 409-414.

190. Gandolfi, O.; Dall'Olio, R.; Roncada, P.; Montanaro, N. NMDA antagonists interact with 5-HT-stimulated phosphatidylinositol metabolism and impair passive avoidance retention in the rat. Neuroscience letters 1990, 113, 304-308.

191. Maura, G.; Marcoli, M.; Pepicelli, O.; Rosu, C.; Viola, C.; Raiteri, M. Serotonin inhibition of the NMDA receptor/nitric oxide/cyclic GMP pathway in human neocortex slices: involvement of 5-HT(2C) and 5- 
HT(1A) receptors. Br J Pharmacol 2000, 130, 1853-1858, doi:10.1038/sj.bjp.0703510.

192. Maura, G.; Raiteri, M. Serotonin 5-HT1D and 5-HT1A receptors respectively mediate inhibition of glutamate release and inhibition of cyclic GMP production in rat cerebellum in vitro. J Neurochem 1996, 66, 203-209.

193. Schmitz, D.; Gloveli, T.; Empson, R.M.; Heinemann, U. Comparison of the effects of serotonin in the hippocampus and the entorhinal cortex. Mol Neurobiol 1998, 17, 59-72, doi:10.1007/BF02802024.

194. Dostal, C.R.; Carson Sulzer, M.; Kelley, K.W.; Freund, G.G.; McCusker, R.H. Glial and tissue-specific regulation of Kynurenine Pathway dioxygenases by acute stress of mice. Neurobiol Stress 2017, 7, 1-15, doi:10.1016/j.ynstr.2017.02.002.

195. Weiland, N.G.; Orchinik, M.; Tanapat, P. Chronic corticosterone treatment induces parallel changes in N-methyl-D-aspartate receptor subunit messenger RNA levels and antagonist binding sites in the hippocampus. Neuroscience 1997, 78, 653-662.

196. Heyes, M.P.; Saito, K.; Lackner, A.; Wiley, C.A.; Achim, C.L.; Markey, S.P. Sources of the neurotoxin quinolinic acid in the brain of HIV-1infected patients and retrovirus-infected macaques. FASEB $J$ 1998, 12, 881-896.

197. Parrott, J.M.; Redus, L.; O'Connor, J.C. Kynurenine metabolic balance is disrupted in the hippocampus following peripheral lipopolysaccharide challenge. J Neuroinflammation 2016, 13, 124, doi:10.1186/s12974016-0590-y. 
198. Sternberg, E.M.; Van Woert, M.H.; Young, S.N.; Magnussen, I.; Baker, H.; Gauthier, S.; Osterland, C.K. Development of a scleroderma-like illness during therapy with L-5-hydroxytryptophan and carbidopa. $N$ Engl J Med 1980, 303, 782-787, doi:10.1056/NEJM198010023031403.

199. Christensen, L.; Redig, C. Effect of meal composition on mood. Behav Neurosci 1993, 107, 346-353.

200. Fernstrom, M.H.; Fernstrom, J.D. Brain tryptophan concentrations and serotonin synthesis remain responsive to food consumption after the ingestion of sequential meals. The American journal of clinical nutrition 1995, 61, 312-319, doi:10.1093/ajcn/61.2.312.

201. Kan, H.; London, S.J.; Chen, G.; Zhang, Y.; Song, G.; Zhao, N.; Jiang, L.; Chen, B. Season, sex, age, and education as modifiers of the effects of outdoor air pollution on daily mortality in Shanghai, China: The Public Health and Air Pollution in Asia (PAPA) Study. Environ Health Perspect 2008, 116, 1183-1188, doi:10.1289/ehp.10851.

202. Furuzawa-Carballeda, J.; Hernandez-Molina, G.; Lima, G.; RiveraVicencio, Y.; Ferez-Blando, K.; Llorente, L. Peripheral regulatory cells immunophenotyping in primary Sjogren's syndrome: a cross-sectional study. Arthritis Res Ther 2013, 15, R68, doi:10.1186/ar4245.

203. Legany, N.; Berta, L.; Kovacs, L.; Balog, A.; Toldi, G. The role of B7 family costimulatory molecules and indoleamine 2,3-dioxygenase in primary Sjogren's syndrome and systemic sclerosis. Immunol Res 2017, 65, 622-629, doi:10.1007/s12026-016-8880-0.

204. James, K.; Al-Ali, S.; Tarn, J.; Cockell, S.J.; Gillespie, C.S.; Hindmarsh, V.; Locke, J.; Mitchell, S.; Lendrem, D.; Bowman, S., et al. A 
Transcriptional Signature of Fatigue Derived from Patients with Primary Sjogren's Syndrome. PLoS One 2015, 10, e0143970, doi:10.1371/journal.pone.0143970.

205. Hall, J.C.; Baer, A.N.; Shah, A.A.; Criswell, L.A.; Shiboski, C.H.; Rosen, A.; Casciola-Rosen, L. Molecular Subsetting of Interferon Pathways in Sjogren's Syndrome. Arthritis Rheumatol 2015, 67, 2437-2446, doi:10.1002/art.39204.

206. Valim, V.; Zandonade, E.; Brun, J.G.; Jonsson, R.; Ueland, P.; Mydel, P.M. Kynurenines pathway biomarkers for primary Sjögren's syndrome. Clin Exp Rheumatol 2018, 36, S-290.

207. Ter Borg, E.J.; Kelder, J.C. Is extra-glandular organ damage in primary Sjogren's syndrome related to the presence of systemic autoantibodies and/or hypergammaglobulinemia? A long-term cohort study with 110 patients from the Netherlands. Int J Rheum Dis 2017, 20, 875881, doi:10.1111/1756-185X.13070.

208. Kivity, S.; Katzav, A.; Arango, M.T.; Landau-Rabi, M.; Zafrir, Y.; Agmon-Levin, N.; Blank, M.; Anaya, J.M.; Mozes, E.; Chapman, J., et al. 16/6-idiotype expressing antibodies induce brain inflammation and cognitive impairment in mice: the mosaic of central nervous system involvement in lupus. BMC Med 2013, 11, 90, doi:10.1186/1741-701511-90.

209. Mariette, X.; Roux, S.; Zhang, J.; Bengoufa, D.; Lavie, F.; Zhou, T.; Kimberly, R. The level of BLyS (BAFF) correlates with the titre of autoantibodies in human Sjogren's syndrome. Ann Rheum Dis 2003, $62,168-171$. 
210. Gottenberg, J.E.; Cagnard, N.; Lucchesi, C.; Letourneur, F.; Mistou, S.; Lazure, T.; Jacques, S.; Ba, N.; Ittah, M.; Lepajolec, C., et al. Activation of IFN pathways and plasmacytoid dendritic cell recruitment in target organs of primary Sjogren's syndrome. Proc Natl Acad Sci U S A 2006, 103, 2770-2775, doi:10.1073/pnas.0510837103.

211. Grisius, M.M.; Bermudez, D.K.; Fox, P.C. Salivary and serum interleukin 6 in primary Sjogren's syndrome. J Rheumatol 1997, 24, 1089-1091.

212. Der, S.D.; Zhou, A.; Williams, B.R.; Silverman, R.H. Identification of genes differentially regulated by interferon alpha, beta, or gamma using oligonucleotide arrays. Proc Natl Acad Sci U S A 1998, 95, 1562315628.

213. Quartuccio, L.; Salvin, S.; Fabris, M.; Maset, M.; Pontarini, E.; Isola, M.; De Vita, S. BLyS upregulation in Sjogren's syndrome associated with lymphoproliferative disorders, higher ESSDAI score and B-cell clonal expansion in the salivary glands. Rheumatology (Oxford, England) 2013, 52, 276-281, doi:10.1093/rheumatology/kes180.

214. Akpek, E.K.; Lindsley, K.B.; Adyanthaya, R.S.; Swamy, R.; Baer, A.N.; McDonnell, P.J. Treatment of Sjögren's syndrome-associated dry eye an evidence-based review. Ophthalmology 2011, 118, 1242-1252, doi:S0161-6420(10)01330-8 [pii]

10.1016/j.ophtha.2010.12.016.

215. Bowman, S.J. Biologic therapies in primary Sjögren's syndrome. Curr Pharm Biotechnol 2012, 13, 1997-2008. 
216. Ramos-Casals, M.; Brito-Zerón, P.; Sisó-Almirall, A.; Bosch, X.; Tzioufas, A.G. Topical and systemic medications for the treatment of primary Sjögren's syndrome. Nature reviews. Rheumatology 2012, 8, 399-411, doi:nrrheum.2012.53 [pii]

10.1038/nrrheum.2012.53.

217. Both, T.; Dalm, V.A.; van Hagen, P.M.; van Daele, P.L. Reviewing primary Sjogren's syndrome: beyond the dryness - From pathophysiology to diagnosis and treatment. Int J Med Sci 2017, 14, 191-200, doi:10.7150/ijms.17718.

218. Sthoeger, Z.; Sharabi, A.; Asher, I.; Zinger, H.; Segal, R.; Shearer, G.; Elkayam, O.; Mozes, E. The tolerogenic peptide hCDR1 immunomodulates cytokine and regulatory molecule gene expression in blood mononuclear cells of primary Sjogren's syndrome patients. Clin Immunol 2018, 192, 85-91, doi:10.1016/j.clim.2018.05.001.

219. Chiarugi, A.; Carpenedo, R.; Molina, M.T.; Mattoli, L.; Pellicciari, R.; Moroni, F. Comparison of the neurochemical and behavioral effects resulting from the inhibition of kynurenine hydroxylase and/or kynureninase. J Neurochem 1995, 65, 1176-1183.

220. Carpenedo, R.; Chiarugi, A.; Russi, P.; Lombardi, G.; Carla, V.; Pellicciari, R.; Mattoli, L.; Moroni, F. Inhibitors of kynurenine hydroxylase and kynureninase increase cerebral formation of kynurenate and have sedative and anticonvulsant activities. Neuroscience 1994, 61, 237-243.

221. Pellicciari, R.; Natalini, B.; Costantino, G.; Mahmoud, M.R.; Mattoli, L.; Sadeghpour, B.M.; Moroni, F.; Chiarugi, A.; Carpenedo, R. Modulation 
of the kynurenine pathway in search for new neuroprotective agents. Synthesis and preliminary evaluation of (m-nitrobenzoyl)alanine, a potent inhibitor of kynurenine-3-hydroxylase. J Med Chem 1994, 37, 647-655.

222. Kocki, T.; Luchowski, P.; Luchowska, E.; Wielosz, M.; Turski, W.A.; Urbanska, E.M. L-cysteine sulphinate, endogenous sulphur-containing amino acid, inhibits rat brain kynurenic acid production via selective interference with kynurenine aminotransferase II. Neurosci Lett 2003, $346,97-100$.

223. Luchowski, P.; Kocki, T.; Urbanska, E.M. N(G)-nitro-L-arginine and its methyl ester inhibit brain synthesis of kynurenic acid possibly via nitric oxide-independent mechanism. Pol J Pharmacol 2001, 53, 597-604.

224. Agudelo, L.Z.; Femenia, T.; Orhan, F.; Porsmyr-Palmertz, M.; Goiny, M.; Martinez-Redondo, V.; Correia, J.C.; Izadi, M.; Bhat, M.; SchuppeKoistinen, I., et al. Skeletal muscle PGC-1alpha1 modulates kynurenine metabolism and mediates resilience to stress-induced depression. Cell 2014, 159, 33-45, doi:10.1016/j.cell.2014.07.051.

225. Barth, M.C.; Ahluwalia, N.; Anderson, T.J.; Hardy, G.J.; Sinha, S.; Alvarez-Cardona, J.A.; Pruitt, I.E.; Rhee, E.P.; Colvin, R.A.; Gerszten, R.E. Kynurenic acid triggers firm arrest of leukocytes to vascular endothelium under flow conditions. J Biol Chem 2009, 284, 1918919195, doi:10.1074/jbc.M109.024042.

226. Kwidzinski, E.; Bunse, J.; Aktas, O.; Richter, D.; Mutlu, L.; Zipp, F.; Nitsch, R.; Bechmann, I. Indolamine 2,3-dioxygenase is expressed in 
the CNS and down-regulates autoimmune inflammation. FASEB $J$ 2005, 19, 1347-1349, doi:10.1096/fj.04-3228fje.

227. Chiarugi, A.; Cozzi, A.; Ballerini, C.; Massacesi, L.; Moroni, F. Kynurenine 3-mono-oxygenase activity and neurotoxic kynurenine metabolites increase in the spinal cord of rats with experimental allergic encephalomyelitis. Neuroscience 2001, 102, 687-695.

228. Flanagan, E.M.; Erickson, J.B.; Viveros, O.H.; Chang, S.Y.; Reinhard, J.F., Jr. Neurotoxin quinolinic acid is selectively elevated in spinal cords of rats with experimental allergic encephalomyelitis. J Neurochem 1995, 64, 1192-1196.

229. Paul, C.; Bolton, C. Modulation of blood-brain barrier dysfunction and neurological deficits during acute experimental allergic encephalomyelitis by the $\mathrm{N}$-methyl-D-aspartate receptor antagonist memantine. J Pharmacol Exp Ther 2002, 302, 50-57.

230. Schroecksnadel, K.; Winkler, C.; Wirleitner, B.; Schennach, H.; Fuchs, D. Aspirin down-regulates tryptophan degradation in stimulated human peripheral blood mononuclear cells in vitro. Clin Exp Immunol 2005, 140, 41-45, doi:10.1111/j.1365-2249.2005.02746.x.

231. Edwards, S.R.; Mather, L.E. Diclofenac increases the accumulation of kynurenate following tryptophan pretreatment in the rat: a possible factor contributing to its antihyperalgesic effect. Inflammopharmacology 2003, 11, 277-292, doi:10.1163/156856003322315622.

232. Jorge, A.G.; Modulo, C.M.; Dias, A.C.; Braz, A.M.; Filho, R.B.; Jordao, A.A., Jr.; de Paula, J.S.; Rocha, E.M. Aspirin prevents diabetic 
oxidative changes in rat lacrimal gland structure and function.

Endocrine 2009, 35, 189-197.

233. Tong, L.; Wong, T.Y. Aspirin and dry eye? Ophthalmology 2009, 116, 167-167 e161, doi:10.1016/j.ophtha.2008.07.001.

234. Yazici, A.; Sari, E.; Ayhan, E.; Sahin, G.; Tiskaoglu, N.S.; Gurbuzer, T.; Kurt, H.; Ermis, S.S. The Effect of Low-Dose Aspirin on Dry Eye Parameters and Ocular Surface Disease Index Questionnaire. J Ocul Pharmacol Ther 2018, 34, 256-259, doi:10.1089/jop.2017.0064.

235. Liu, R.; Su, D.; Zhou, M.; Feng, X.; Li, X.; Sun, L. Umbilical cord mesenchymal stem cells inhibit the differentiation of circulating $\mathrm{T}$ follicular helper cells in patients with primary Sjogren's syndrome through the secretion of indoleamine 2,3-dioxygenase. Rheumatology (Oxford, England) 2015, 54, 332-342,

doi:10.1093/rheumatology/keu316.

236. Yaksh, T.L.; Schwarcz, R.; Snodgrass, H.R. Characterization of the Effects of L-4-Chlorokynurenine on Nociception in Rodents. The journal of pain : official journal of the American Pain Society 2017, 18, 11841196, doi:10.1016/j.jpain.2017.03.014.

237. Elmaagacli, A.H.; Ditschkowski, M.; Steckel, N.K.; Gromke, T.; Ottinger, H.; Hillen, U.; Baba, H.A.; Trenschel, R.; Beelen, D.W.; Koldehoff, M. Human chorionic gonadotropin and indolamine 2,3-dioxygenase in patients with GVHD. Bone Marrow Transplant 2014, 49, 800-805, doi:10.1038/bmt.2014.59. 
238. Gajewski, T.F.; Schreiber, H.; Fu, Y.X. Innate and adaptive immune cells in the tumor microenvironment. Nat Immunol 2013, 14, 1014-1022, doi:10.1038/ni.2703.

239. Beatty, G.L.; O'Dwyer, P.J.; Clark, J.; Shi, J.G.; Bowman, K.J.; Scherle, P.A.; Newton, R.C.; Schaub, R.; Maleski, J.; Leopold, L., et al. First-inHuman Phase I Study of the Oral Inhibitor of Indoleamine 2,3Dioxygenase-1 Epacadostat (INCB024360) in Patients with Advanced Solid Malignancies. Clin Cancer Res 2017, 23, 3269-3276, doi:10.1158/1078-0432.CCR-16-2272. 